\title{
Pratiques
}

Linguistique, littérature, didactique

173-174| 2017

Le déjà-là dans l'écriture

\section{Chaines de reformulation dans un corpus de production-traduction}

Les influences du déjà-dit dans des écritures-réécritures traductionnelles

Reformulating in writing and translation process corpus

\section{Christophe Leblay et Tarja Leblay}

\section{OpenEdition}

\section{Journals}

Édition électronique

URL : http://journals.openedition.org/pratiques/3325

DOI : $10.4000 /$ pratiques.3325

ISSN : 2425-2042

Éditeur

Centre de recherche sur les médiations (CREM)

Référence électronique

Christophe Leblay et Tarja Leblay, « Chaines de reformulation dans un corpus de production-

traduction », Pratiques [En ligne], 173-174 | 2017, mis en ligne le 10 mars 2017, consulté le 20 avril

2019. URL : http://journals.openedition.org/pratiques/3325 ; DOI : 10.4000/pratiques.3325

Ce document a été généré automatiquement le 20 avril 2019.

(c) Tous droits réservés 


\title{
Chaines de reformulation dans un corpus de production-traduction
}

Les influences du déjà-dit dans des écritures-réécritures traductionnelles Reformulating in writing and translation process corpus

\author{
Christophe Leblay et Tarja Leblay
}

1 Les études consacrées aux liens entre traduction et production écrite restent pour l'essentiel récentes (Dam-Jensen \& Heine, 2009; Gambier, 2012 ; Dam-Jensen \& Heine, 2013 ; Salmi, 2014) et plutôt confidentielles. Nous pensons que la première reste un cas particulier de la seconde; dans cette perspective, nous parlerons alors plus volontiers de scripteurtraducteur que de traducteur à proprement parler. Nous envisagerons de réaliser notre étude dans le cadre théorique des approches génétiques qui prennent en compte prioritairement les différentes versions successives d'une même écriture, avant de s'intéresser au seul produit final.

2 L'idée est bien de positionner, de manière complémentaire, la génétique textuelle parmi les autres disciplines de l'écriture et de montrer que celle-ci offre une véritable opportunité de décryptage de l'écriture numérique outillée. Loin donc d'être réduite au silence, la méthodologie de la génétique textuelle permet une appréhension pertinente du monde contemporain de l'écriture dont fait partie la traduction. Nous allons, pour commencer, nous interroger sur les apports de la génétique textuelle à une écriture traductionnelle, en lien à d'autres approches connexes, avant de présenter notre corpus et la méthodologie suivie pour ce travail (écritures nouvelles référées à des écritures antérieures). Nous analyserons enfin, dans certaines chaines de reformulation, des occurrences de déspécialisation.

\section{Génétique textuelle et écriture traductionnelle}

Dans la perspective d'efficacité communicationnelle exigée par une écriture à visée professionnelle, la génétique textuelle (Grésillon, 1994) occupe une place légitime au 
même titre que les autres disciplines de l'écrit, traditionnellement convoquées comme la psychologie cognitive (Fayol, 1997), ou la didactique de l'écriture (Reuter, 1996). Peu encore mise en pratique dans des enseignements dédiés aux écritures professionnelles, monolingues (rédaction) comme bilingues (traduction), cette méthodologie commence à prendre sa place (Leblay, 2014).

4 Le produit n'est pas la représentation fidèle de la production : chercher à enseigner (uniquement) les processus d'écriture-réécriture traductionnelle à partir du seul produit (appelé traduction dans notre travail) serait illusoire. Il s'avère alors très utile de décrire des phénomènes scripturaux en termes de genèse, et non plus seulement en termes de structure, de clôtures. Il s'agit principalement d'introduire à d'autres représentations de ce qui est en train d'être écrit par le scripteur-traducteur, en apprenant à se passer de celles imposées par des notions comme celle de texte, représentatif d'une forme de clôture.

\section{1. Écriture, écriture de spécialité et écriture traductionnelle}

L'appellation de langues de spécialité (LSP) est apparue vers la fin des années 1960. Par rapport à cette époque-là, la signification de l'appellation a changé radicalement. Selon Y. Gambier (Pratiques 171-142, 2017), il existe trois raisons principales qui ont bousculé nos manières de penser les données, les informations et les messages : 1) la logique des communications d'entreprise, 2) les LSP, et 3) les technologies de l'information (TIC). Y. Gambier constate que les sujets traités de nos jours - par exemple, lors de symposiums européens biennaux sur les langues de spécialité - proviennent des domaines très variés allant des aspects didactiques des LSP, l'évaluation, l'étude de traits linguistiques jusqu'aux domaines spécifiques comme le droit, médecine et ingénierie. Devant ces multiples tendances et ouvertures, Y.Gambier, dans le même article, propose que l'appellation langue de spécialité puisse être considérée comme un hypéronyme dans la mesure « où il est question d'une terminologie et d'une syntaxe spécifique assorties d'une organisation discursive qui vise l'objectivité de la communication dans une discipline donnée ». Nous conservons donc, dans ce travail, l'appellation écriture de spécialité.

6 L'introduction des technologies de l'information, par l'intermédiaire de l'écran, a eu aussi des conséquences déterminantes pour l'enseignement en langue de spécialité et donc en production-traduction. Selon D. Dressen-Hammouda (2006), toute la façon d'aborder le travail d'écriture s'en trouve profondément modifiée. Ces modifications concernent aussi bien nos façons de communiquer et de travailler dans les lieux dédiés à l'apprentissage que dans des lieux où est exercée une pratique professionnelle. La vraie nouveauté serait l'appréhension de l'écriture traditionnelle en écriture multimodale qui existe simultanément sous forme textuelle, électronique ou visuelle. Cet aspect intéresse notre propos dans la mesure où la mise en vision de ce qui est écrit reste une partie essentielle du travail de mise en page. La recommandation serait donc de ne plus focaliser l'enseignement de la langue de spécialité uniquement sur le mode textuel, mais d'élargir l'image du texte en le concevant comme un point de départ, comme une trame, qui servirait à réaliser des tâches dans des modes multiples (ibid.).

D'une manière plus générale, nous cherchons à présenter l'existence d'un continuum, en montrant bien qu'il s'agit du même geste qui traverse toutes ces formes de mise en texte et de mise en page. 


\subsection{Représentations scripturales diplomatique versus linéaire}

8 Le travail d'écriture en traduction pourrait donc suivre la description inaugurée par la génétique textuelle qui propose une distinction élémentaire entre deux modes de représentations (de l'écriture) : les modes diplomatique et linéaire (Grésillon, 1994). Nous proposons d'appliquer cette distinction au travail d'une écriture traductionnelle. Ainsi, serait considérée comme diplomatique une représentation «qui respecte fidèlement la topographie des signifiants graphiques dans l'espace»; bien différemment, une représentation linéaire serait produite sans égard à la topographie et formerait, d'un point de vue génétique, un début d'interprétation, puisque la "verticalité des paradigmes de réécriture est mise à plat et traduite en successivité horizontale» (ibid., p. 246). Nous verrons que, dans le cas du corpus qui nous intéresse, la distinction entre diplomatique et linéaire est une distinction essentielle et peu maitrisée par des étudiants.

Il est nécessaire de remarquer que notre travail prend place dans le cadre d'une didactique de l'écriture traductionnelle, qui n'est donc pas celui d'une pratique de la traduction en milieu professionnel, où les attentes et les contraintes sont bien différentes. Ainsi, fréquemment, le travail de mise en texte, donc d'écriture traductionnelle à proprement parler, est réalisé par des traducteurs, qui n'ont pas à charge le travail de mise en page. Dans cette approche didacticienne, nous avons souhaité pouvoir travailler directement avec les étudiants la qualité linguistique afin de pouvoir faire apparaître certains phénomènes de reformulation. Nous nous sommes donc abstenus d'utiliser certains programmes usuels en pratique professionnelle. Ainsi, ont été évités 2 types de programmes : 1) les mémoires de traduction et 2) les traductions automatiques utilisées en post-édition, de type Google translate. Ces aides à l'écriture traductionnelle auraient changé notre point de vue qui reste celui d'une mise en relation inclusive, d'un seul geste allant du plus générique au plus spécifique :

Écriture $\rightarrow$ Écriture de spécialité/professionnelle $\rightarrow$ Écriture traductionnelle

Ce geste est très bien décrit par la méthodologie génétique : écrire, c'est mettre en succession, en parallèle parfois, des états, des versions, et donc des représentations de ces écritures sans prétendre à l'excellence de l'un(e) sur l'autre. Les unes et les autres se construisent successivement, dans un rapport de complémentarité, non d'exclusion. Cette successivité est au centre du processus qui nous intéresse dans ce travail, où les versions qui se suivent montre un changement qualitatif, parfois radical. Nous proposons alors que cette successivité scripturale prenne le nom de réécriture ${ }^{1}$ dès lors que le scripteur revient dans ce qu'il a déjà écrit.

\section{3. Écriture-réécriture \& auto-évaluation}

11 Notre travail se situant dans le cadre d'une didactique de l'écriture traductionnelle, il importe que les étudiants arrivent à évaluer leur propre manière de travailler et à agir en tant que scripteur-traducteur. Nous proposons donc d'introduire, dans ce travail, quelques réflexions et conceptions provenant de domaines connexes comme celle de l' auto-évaluation.

12 En contexte scolaire, l'enseignement de ce qui a été traditionnellement nommé traduction a été une des méthodes les plus utilisées en langues étrangères. Dans ce contexte-là, l'apprentissage des langues étrangères s'est réalisé via la traduction de phrases isolées, 
totalement décontextualisées. Ce qui importait était surtout la maîtrise grammaticale et lexicale de structures linguistiques entre une langue source et une langue cible. En réaction à cette pratique, les années 1970 ont vu des changements radicaux se mettre en place. Le contexte sociétal changeant, il apparaissait alors aussi en didactique des langues des points de vue innovateurs qui accentuaient l'importance de passer d'une pédagogie dirigée par l'enseignant à une pédagogie centrée sur l'apprenant et ses besoins (Lussier \& Turner, 1995, p. 41-42). Le Conseil de l'Europe a été, dès les années 1970, un précurseur dans l'apprentissage des langues vivantes: il a donc lancé plusieurs projets pilotes, réalisés en coopération élargie, dont le but a été de créer des outils et des mesures permettant, entre autres, à l'apprenant de prendre en main et de diriger ses propres projets (Trim, 2007, p. 26-27). C'est dans ce contexte éducatif renouvelé qu'est apparu un faisceau de conceptions autour de l'auto-évaluation: l'autonomie de l'apprenant, l'apprentissage tout au long de la vie et apprendre à apprendre.

Vers les années 1980, avec l'arrivée de l'approche communicative de l'enseignement des langues, le rôle de la traduction (comme exercice grammatical) a graduellement perdu son importance principale au profit des approches développées par l'évaluation de la compétence langagière (Tsagari \& Floros, 2013). L'auto-évaluation devient une approche centrale pour ceux qui s'intéressent à l'autonomie de l'apprenant ou à l'apprentissage tout au long de la vie (Barbot, 1990; Oscarson, 1997). Les compétences réflexives à acquérir sont donc mises au cœur aussi bien de l'apprentissage des langues que de la mise en œuvre du travail professionnel. Il est attendu que les différents agents acceptent d'être une partie responsable tant de leur capacité d'évaluation professionnelle que de leur conscience éthique (Lucas \& Tan, 2013, p. 104). La fiabilité de l'auto-évaluation a été, comme on peut s'y attendre, beaucoup discutée pendant. La majorité des travaux concentrant sur sa fiabilité ont néanmoins montré des preuves d'un lien plutôt fort entre l'auto-évaluation et l'évaluation externe de la compétence langagière de l'apprenant (par exemple LeBlanc \& Painchaud, 1985 ; Lee-Ellis, 2009 ; Leblay, 2013).

En plus de l'auto-évaluation, il existe des méthodes d'évaluation dites alternatives, comme les évaluations diagnostique, formative et dynamique, qui sont tout autant concernées que la génétique du texte par le processus d'écriture, à la différence de l'évaluation sommative qui reste centrée sur le texte achevé. Ces trois premières méthodologies évaluatives ont en commun la recherche de l'information des points forts (et des points faibles) lors des processus de production d'un scripteur afin de pouvoir le guider le mieux dans une direction souhaitée. Nous comprenons que dans le terme d' évaluation, il se trouve celui de valeur : il s'agit bien de donner de la valeur aux acquis.

L'entraînement à l'auto-évaluation de soi, de son travail ou de celui des autres, l'évaluation mutuelle, aussi bien que le feedback continuellement reçu de la part de l'enseignant, font partie des compétences universitaires. La réécriture peut être faite, selon les cas et les besoins, seul, entre pairs, ou sous la direction d'un enseignant. Dans cette étude, l'écriture-réécriture a été faite seule, mais elle a précédé (écriture), et succédé (réécriture) à une discussion commune en classe dont le résultat a été une proposition négociée ensemble d'une partie du texte. 


\section{Corpus \& méthodologie}

\subsection{Corpus \& sous-corpus}

Le corpus est composé de deux textes rédigés en finnois (Annexes 1 \& 2) : le premier concerne le domaine de la bio-économie, le second celui des mathématiques appliquées. De ce corpus, nous avons extrait quatre sous-corpus, distribués de la manière suivante (tableau 1) :

Tableau 1. Sous-corpus

\begin{tabular}{|c|c|c|c|c|}
\hline $\begin{array}{l}\text { Sous- } \\
\text { corpus }\end{array}$ & $\begin{array}{l}\text { Domaine de } \\
\text { spécialité }\end{array}$ & Énoncés sources en finnois & Consigne & $\begin{array}{l}\text { Représentation } \\
\text { de l'écriture }\end{array}$ \\
\hline 1 & Bioéconomie & $\begin{array}{l}\text { Entsyymejä kehittävä } \\
\text { valittu maailman }\end{array}$ & \multirow{4}{*}{$\begin{array}{l}\text { Traduisez de } \\
\text { l'information } \\
\text { spécialisée à } \\
\text { destination du } \\
\text { grand public } \\
\text { (presse). }\end{array}$} & Diplomatique \\
\hline 2 & \multirow{3}{*}{$\begin{array}{l}\text { Mathématiques } \\
\text { appliquées }\end{array}$} & $\begin{array}{l}\text { Perustaltaan graafiteoria on } \\
\text { kombinatoriikkaa, jossa ei sinänsä } \\
\text { tarvita "grafiikkaa" muutoin kuin } \\
\text { havainnollistamiseen. }\end{array}$ & & \multirow{3}{*}{ Linéaire } \\
\hline 3 & & $\begin{array}{lr}\text { Graafiteorian sovelluksiin ja } \\
\text { mallintamiseen liittyy kuitenkin } \\
\text { yleensä tilanteeseen } & \text { sopivan } \\
\text { fysikaalis-geometrisen } & \text { esityksen } \\
\text { antama kontakti "reaalimaailmaan" } \\
\text { ja toisaalta } & \text { kombinatoris- } \\
\text { lineaarialgebrallisen } & \text { koneiston } \\
\text { antama matemaattinen } & \text { määrittely- } \\
\text { ja laskukyky. }\end{array}$ & & \\
\hline 4 & & $\begin{array}{l}\text { Graafiteorian tulosten ja } \\
\text { menetelmien todistuksia ja johtoja ei } \\
\text { yleensä esitetä jäykän } \\
\text { kombinatorisessa muodossa, vaan } \\
\text { käyttäen tehokkaasti hyväksi } \\
\text { graafisen esityksen antamaa } \\
\text { havainnollistamismahdollisuutta }\end{array}$ & & \\
\hline
\end{tabular}

17 Pour des raisons pratiques, nous avons fait correspondre segment et phrase, et avons présenté ces segments dans des tableaux qui se trouvent en fin d'article (Annexe 3). Cette présentation nous permet d'aligner facilement les différentes versions, au regard des 4 textes-sources qui occupent la colonne centrale. La consigne, colonne 4, insiste sur l'idée que la traduction est réalisée en vue d'un destinataire connu, avec ses exigences propres. En cela, l'écriture traductionnelle ne se différentie pas non plus de l'écriture. Enfin, est 
notée, dans la colonne 5, l'alternative entre deux modes de représentation standardisée : les modes diplomatique et linéaire.

\section{Comparateurs textuels : le cas de MEDITE}

Dans cette étude, a été utilisé un logiciel de comparaison de versions, nommé MEDITE, conçu par les chercheurs de l'Institut des Textes et Manuscrits Modernes (ITEM) en collaboration avec Jean-Gabriel Ganascia (Fenoglio, Lebrave \& Ganascia, 2007). Selon ces auteurs, il s'agit d'un programme qui repère automatiquement les opérations d'écriture qui font passer d'un texte à un autre. MEDITE comprend également une interface graphique permettant de visualiser les modifications opérées par les opérations d'écriture (ajouts, suppressions, déplacements ou remplacements de blocs de caractères) faisant passer d'un état du texte à un autre, d'une version à une autre.

Figure 1. Interface de MEDITE [http://obvil-dev.paris-sorbonne.fr/medite/]

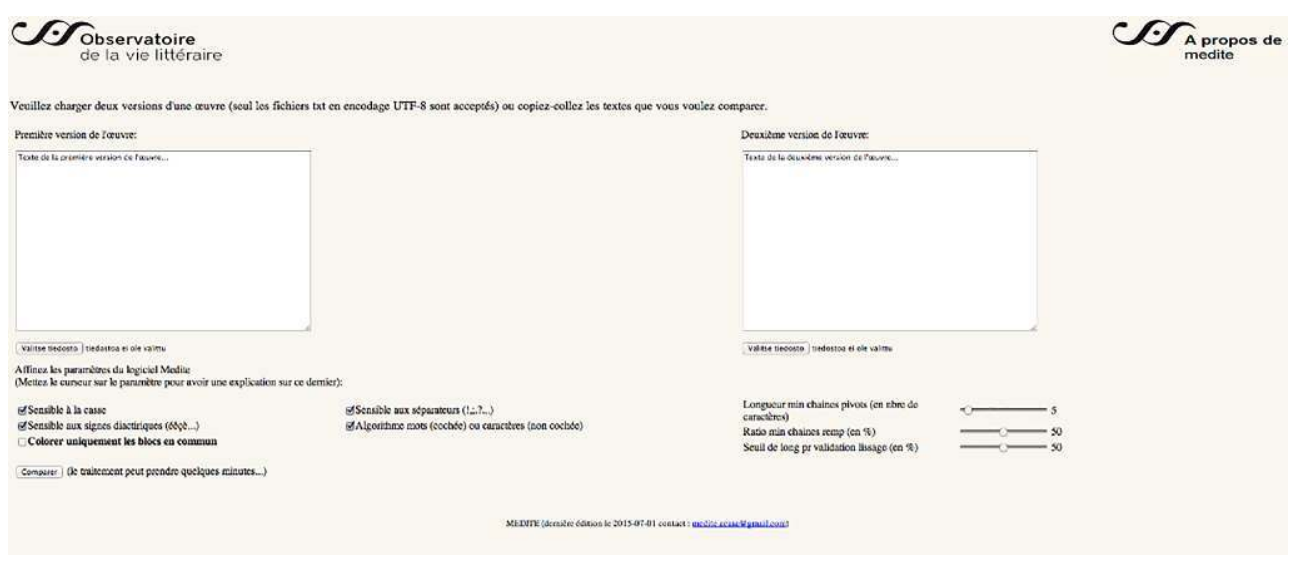

Deux fenêtres montrent l'emplacement respectif des versions à comparer : la fenêtre de gauche est réservée à une version antérieure (la version 1 , dans notre travail), celle de droite est réservée à une version postérieure (la version $2 b$, dans notre travail).

MEDITE autorise un certain paramétrage $: 5$ options sont à cocher, ou pas : 1) Sensible à la casse, 2) Sensible aux signes diacritiques, 3) Colorer uniquement les blocs en commun, 4) Sensible aux séparateurs et 5) Algorithme mots ou caractères. À ces 5 options, 3 réglages sont possibles: Un pour la longueur minimale des chaines pivots (en nombre de caractères, un pour le ratio minimal des chaines remplacées en \%, et un dernier pour le seuil de longueur par validation en \%. Nous avons choisi les 5 options et effectué les réglages comme suit : Longueur : 5 . Ratio : 10 . Seuil : 10 .

\section{Tâches}

Cette contribution se propose d'étudier le phénomène de reformulation dans un corpus de production-traduction. Pour cela, deux versions du même texte ont été demandées à des étudiants en Master de traduction professionnelle ${ }^{2}$ : ont donc été réalisées au total 84 productions, dans un environnement numérique, à la suite d'un déjà donné précis représenté par des textes-sources à traduire. Pour notre corpus, nous avons choisi deux de ces textes-sources, pris dans deux discours de spécialité différents (la bio-économie et les mathématiques), tous deux rédigés en finnois. 
Le déjà-là est alors doublement présent : une première fois, sous la forme du texte-source, donné en finnois, et une seconde fois, sous la forme d'une proposition discutée en français, par l'enseignant (cf. phase 2). L'idée a bien été d'introduire du déjà-dit et d'en mesurer l'impact sur les réécritures-traductions. forme diplomatique, se présente comme un document avec une mise en page bien particulière: alignement sur trois colonnes, utilisation des couleurs et d'images, hiérarchisation de l'information avec usage de diverses polices de tailles différentes. Ce texte se compose donc d'éléments très variés qui nécessitent un savoir-faire numérique de la part des étudiants avant d'aboutir à un texte qui représente au mieux le textesource (Annexe 1).

Le second texte, extrait d'un texte de mathématiques appliquées, est représenté sous une forme linéaire. Il s'agit donc pour les étudiants de se concentrer sur la qualité linguistique et textuelle, sans avoir à se préoccuper du visuel du texte (Annexe 2).

\subsection{Méthodologie}

\section{Écriture traductionnelle successive}

Plus précisément, le protocole mis en place a consisté à demander aux scripteurstraducteurs de réaliser, à titre individuel, une première écriture-traduction complète d'un texte spécialisé, vers le français. Cette première écriture-traduction a, à son tour, permis une mise en commun, où il s'est agi de discuter du premier tiers du texte, sous la direction de l'enseignant. Cette reprise partielle, à son tour, a donné lieu à une seconde version, une réécriture-traduction, réalisée de nouveau individuellement, de la suite du texte. Dans la présente étude, le processus d'écriture-traduction s'est donc déroulé en trois phases distinctes qui sont présentées dans le tableau ci-dessous (tableau 2).

Tableau 2. Les phases du protocole

\begin{tabular}{|l|l|l|l|}
\hline Phases & $\begin{array}{l}\text { Caractéristiques du processus } \\
\text { d'écriture }\end{array}$ & \multicolumn{2}{|l|}{ Modalités } \\
\hline 1 & $\begin{array}{l}\text { Travail d'écriture individuel } \\
\text { de la totalité du texte }\end{array}$ & $\begin{array}{l}\text { En travail } \\
\text { autonome }\end{array}$ & $\begin{array}{l}\text { Représentation } \\
\text { linéaire }\end{array}$ \\
\hline 2 & $\begin{array}{l}\text { Traitement commun et négocié } \\
\text { du début de la version 1 }\end{array}$ & En présentiel & $\begin{array}{l}\text { Représentation } \\
\text { linéaire }\end{array}$ \\
\hline 3 & Travail de réécriture individuelle & En & travail \\
(Version 2b) & de la fin du texte & $\begin{array}{l}\text { linéaire (texte 2) } \\
\text { ou donome } \\
\text { (texte 1) }\end{array}$ \\
\hline
\end{tabular}




\section{Phase 1 - Production de la version 1}

finnois en français. Tant le texte-source sur la bio-économie que celui traitant de mathématiques appliquées, a donné lieu à une consigne identique: «Traduisez de l'information spécialisée à destination du grand public (presse)».

\section{Phase 2 - Production de la version $2 a$}

Ensuite, sur la base de leurs recherches documentaires et de leurs premières versions, les étudiants ont pu continuer de travailler ensemble en présentiel, durant le cours, une partie du texte déjà traduit. La méthode pratiquée en cours a été volontairement concentrée sur les étudiants ; le rôle de l'enseignant a été uniquement celui de participant. Cette volonté de laisser plus d'espace pour la discussion et pour la coopération dans l'interprétation du texte traduit, s'est concrétisée par le fait qu'une étudiante, dont le nom a été tiré au sort, s'est chargée de la rédaction de cette deuxième version, sous la dictée des autres. Seul le début du texte a été discuté et réécrit ensemble, tandis que le reste du texte était de nouveau à la charge de chacun des étudiants. La discussion commune réalisée en cours pourrait représenter ce que R. Ellis (2005, p. 228) appelle l'évaluation coopérative dont le but est de montrer ce que les étudiants sont capables de faire en coopération les uns avec les autres bien plus que ce qu'ils arrivent à faire seuls, les uns sans les autres. Cette remarque est, bien évidemment, d'une importance primordiale, compte tenu des attentes professionnelles auxquelles les étudiants vont devoir faire face dans leur vie.

Cette version 2 réalisée en cours (dorénavant version 2a), n'est qu'une reprise partielle du texte : l'objectif a été de pointer certains phénomènes de déspécialisation. Nous désignons, par ce dernier terme, le phénomène qui fait passer une écriture de spécialité à une écriture moins spécialisée, à la différence d'une écriture de spécialité qui fait passer d'une écriture commune à une écriture de spécialité (Condamines, 2003 ; Condamines \& Picton, 2014). Pour évoquer ce phénomène de déspécialisation, avec d'autres termes, X. Galisson (1978) parlera de banalisation lexicale, tandis que I. Meyer et K. Mackintosh (2000), parleront de déterminologisation, migration, voire de dilution. La déspécialisation n'est pas pour autant la vulgarisation qui reste un projet plutôt explicite, didactique, de mise à portée du grand public d'une connaissance spécialisée : La déspécialisation s'en distingue par des manifestations linguistiques précises, mais moins directes que dans le cas de la vulgarisation. Six manifestations sont généralement citées: Mots ou groupes de mots inconnus (création lexicale), fréquence inattendue, structures elliptiques (absence de déterminant/préposition), combinaisons anormales de mots ou groupes de mots, anomalie sémantique d'un argument et coordination inattendue (Condamines \& Picton, 2003). Toutes ne se réalisent pas dans une même écriture. Pour schématiser, nous pourrions dire qu'une écriture de spécialité est davantage caractérisée par une forte nominalisation et une faible présence de constructions verbales, tandis qu'une écriture déspécialisée est davantage caractérisée par une absence de nominalisation et une présence marquée de constructions verbales. C'est donc bien sur l'opposition entre nominalisation et construction verbale qu'il faut porter son attention. La presse reste le commanditaire privilégié de ce genre d'écriture, en offrant, à une partie de son lectorat, une information, qui, bien que très proche d'un domaine de spécialité, est 
linguistiquement dégagée de certaines marques, en particulier de la forte présence de nominalisation.

La reprise en commun de la version 1, rédigée individuellement, a eu pour but de mettre en relief certaines de ces caractéristiques. Le texte-source a été choisi pour ses marques qui devaient être retraduites par des constructions verbales. Le finnois, ayant tendance à nominaliser davantage que le français, devrait offrir un terrain de choix, en principe.

\section{Phase 3 - Production de la version $2 b$}

Enfin, à la suite de la séance commune réalisée en classe, il a été demandé aux étudiants de reprendre une nouvelle fois l'intégralité de leur texte (dorénavant version $2 b$ ), à partir de ce qui a été réécrit ensemble. La consigne de réécriture, donnée oralement, a été explicitement de se servir de ce début du texte négocié ensemble pour reprendre la suite.

L'idée dans ce type d'approche a été de pouvoir voir comment ce qui a été déjà écrit en classe va influencer ce qui va être écrit après le cours. Le but de la phase 3 a donc été de revoir l'écriture de son texte à l'aide des discussions entretenues et des propositions d'interprétation différentes faites en classe. À ce point, il reste à faire remarquer que les étudiants ont été libres de manipuler, ou non, leurs traductions déjà faites auparavant. Cette remarque concerne également l'étendue d'éventuelles modifications à faire. Nous avons voulu voir s'il était possible d'intervenir sur l'écriture d'un scripteur, ici traducteur, sans avoir à corriger individuellement chaque copie produite.

\section{Les déjà-écrits}

Nous cherchons à défaire un schéma, trop simpliste, et malgré tout, très présent chez les étudiants, selon lequel, il s'agirait de prendre un simple appui sur un tout premier texte donné, le texte consigne, pour produire un second et donc unique texte qui serait, dans le cas qui nous concerne, le texte traduit. Ce qui se passe entre ces deux pôles est bien plus fécond : s'il existe bien, dans le cas de l'écriture traductionnelle, un tout premier texte explicite, il est loin d'être le seul à servir d'appui à une réécriture. Il existe un nombre, non limité ${ }^{3}$ d'écritures intermédiaires entre ce tout premier texte-source et celui qui sera nommé, bien plus tard, traduction. Il serait donc plus juste de parler de déjà-écrits, au pluriel.

Dans la successivité qui va se construire, il est, malgré tout, pertinent de voir, et surtout de montrer à voir, comment ce qui précède influence, en principe, ce qui va suivre, dans un mouvement progressif qui va du déjà dit au qui est à redire.

Tableau 3. Écriture traductionnelle

\begin{tabular}{|c|c|c|c|c|}
\hline \multirow{4}{*}{ Texte-source } & \multicolumn{4}{|c|}{ Écriture traductionnelle } \\
\hline & Version 1 & Version $2 \mathrm{a}$ & Version $2 b$ & \multirow{3}{*}{ Texte-cible } \\
\hline & \multicolumn{3}{|c|}{ Retour dans le déjà écrit } & \\
\hline & Écriture & \multicolumn{2}{|c|}{ Réécriture (révision) } & \\
\hline
\end{tabular}



reformulation, en tant qu'écritures nouvelles référées à des écritures antérieures, en pointant plus précisément certaines chaines de réécriture présentes dans les deux versions successives. Nous cherchons à mettre en évidence l'impact de la proposition discutée en cours d'une partie du texte (version 2a), et si cela peut être à l'origine d'une amélioration ou d'une détérioration de la réécriture du texte (version $2 \mathrm{~b}$ ). Nous allons porter notre attention sur les chaines de reformation qui relèvent 1) de la morphosyntaxe de la langue commune, 2) et de celles qui relèvent de faits de langue de déspécialité. Nous construisons notre réflexion à partir de 4 exemples-types extraits du corpus (Annexe 3). Ceux-ci sont décrits depuis une approche génétique, ce que nous a permis de faire très facilement MEDITE, puisque les réécritures sont notées principalement en opérations d'écriture, c'est-à-dire en ajout, suppression, remplacement ou déplacement (Annexe 4).

\subsection{Chaines de reformulation morphosyntaxiques}

Certaines chaines de reformulation se concentrent principalement sur la reprise de phénomènes morphosyntaxiques, ce qui montre une attention, de la part de certains étudiants, à la qualité de la langue utilisée commune. Nous verrons l'accord en genre et l' anaphore.

Exemple-type (1), sous-corpus 1, Kaisa

L'entreprise MetGenon, active dans la production des enzymes, a été introduit [...]

$\rightarrow$ L'entreprise finlandaise MetGen, active dans la production des enzymes, a été introduite

[...]

Cet exemple est caractéristique des difficultés que peuvent rencontrer certains étudiants dans la maîtrise des accords. Appartiennent à ce groupe d'autres reformulations similaires, regroupées dans le tableau suivant (4):

Tableau 4. Accord en genre

\begin{tabular}{|l|l|l|l|}
\hline $\begin{array}{l}\text { Sous-corpus } \\
1\end{array}$ & Réécriture réussie (V2b) & $\begin{array}{l}\text { Opération } \\
\text { d'écriture }\end{array}$ & $\begin{array}{l}\text { Objet de la } \\
\text { reformulation }\end{array}$ \\
\hline Kaisa & $\begin{array}{l}\text { L'entreprise finlandaise [...]a été } \\
\text { introduite }\end{array}$ & Remplacement & Accord du genre \\
\hline
\end{tabular}




\begin{tabular}{|l|l|l|l|}
\hline Marianna & L'entreprise [...]a été sélectionnée & Remplacement & Accord de genre \\
\hline Elviira & $\begin{array}{l}\text { L'entreprise finlandaise a été } \\
\text { sélectionnée }\end{array}$ & Remplacement & Accord de genre \\
\hline
\end{tabular}

Ainsi, l'accord de genre entre sujet-verbe est une vraie difficulté pour des scripteurs finnophones, étant donné qu'il n'existe pas de genre grammatical en finnois. Il n'est donc pas étonnant que des étudiants de Master aient besoin de réviser de tels accords. Trois étudiants ont ainsi pu réécrire le début du texte, où se manifestaient de tels accords, en réalisant des remplacements.

Mais, à ce comportement, en correspondent d'autres. Ainsi, si Aila n'a pas eu à reprendre les accords puisque ceux-ci ont été correctement réalisés dès la version 1 (entreprise sélectionnée), d'autres ont eu à cœur de choisir, dès la version 1 , des tournures au masculin, comme Eija (Metgen a été choisi), ou même des tournures avec une formulation neutralisée, comme Soila (La compagnie fait partie); ce qui est une stratégie d'écriture efficace.

Le tableau suivant (5) donne à voir un cas très semblable :

Tableau 5. Apposition

\begin{tabular}{|l|l|l|l|}
\hline $\begin{array}{l}\text { Sous- } \\
\text { corpus } 1\end{array}$ & Réécriture réussie (V2b) & $\begin{array}{l}\text { Opération } \\
\text { d'écriture }\end{array}$ & $\begin{array}{l}\text { Objet de la } \\
\text { reformulation }\end{array}$ \\
\hline Nina & $\begin{array}{l}\text { entreprises cleantech (éco- } \\
\text { technologiques) ... }\end{array}$ & Remplacement & Mise en apposition \\
\hline
\end{tabular}

Cette étudiante, attentive, reprend sa première version (éco-technologies) mise entre parenthèses pour la reformuler en (éco-technologiques), toujours entre parenthèses : ce faisant, elle fait d'un substantif un adjectif qui vient s'accorder à entreprises. La valeur explicative de la parenthèse est conservée.

43 À ce premier exemple-type, nous pouvons joindre un deuxième qui relève aussi de chaines de reformulation morphosyntaxique :

Exemple-type (2), sous-corpus 4, Marianna

Les objets et résultats ne sont pas représentés [...]

$\rightarrow$ Ses objets et ses résultats ne sont pas représentés [...]

Avec cet exemple, néanmoins, nous avons voulu regarder si des phénomènes interphrastiques étaient pris en compte dans la réécriture. La reprise anaphorique (possessif + substantif ou démonstratif + substantif) serait attendue, cet énoncé venant après d'autres, où le groupe nominal la théorie des graphes est déjà amplement utilisé précédemment. Deux étudiants réécrivent le texte ainsi, comme le montre le tableau 6 :

Tableau 6. Anaphore

\begin{tabular}{|l|l|l|l|}
\hline $\begin{array}{l}\text { Sous-corpus } \\
4\end{array}$ & Réécriture réussie $(\mathrm{V} 2 \mathrm{~b})$ & $\begin{array}{l}\text { Opérations } \\
\text { d'écriture }\end{array}$ & $\begin{array}{l}\text { Objet da la } \\
\text { reformulation }\end{array}$ \\
\hline
\end{tabular}




\begin{tabular}{|l|l|l|l|}
\hline Marianna & $\begin{array}{l}\text { Ses objets et ses résultats ne sont pas } \\
\text { représentés }\end{array}$ & Remplacement & Reprise anaphorique \\
\hline Nina & ...les méthodes de cette théorie... & Remplacement & Reprise anaphorique \\
\hline
\end{tabular}

Dans l'un et l'autre exemple, la version 2 est bien le lieu et le moment où peut se manifester la reprise de phénomènes complexes comme ceux des anaphores. Ce comportement, qui consiste à travailler les anaphores, est néanmoins présent chez peu de scripteurs, la grande majorité ayant choisi de garder la formulation déjà produite dans la version 1, indépendamment donc de ce que proposait la version commune (version 2a). Notons pourtant qu'il n'est évidemment pas demandé au traducteur-scripteur de réussir d'un seul geste, en une seule écriture, la manipulation de tels phénomènes.

Si ces reformulations concernaient principalement la morphosyntaxe, d'autres se trouvent plus centrées sur des phénomènes plus caractéristiques d'une langue de déspécialité, objets de ce cours de Master.

\subsection{Chaines de reformulation, dites de spécialité}

7 Plusieurs occurrences sont représentées par deux autres exemples-types, l'un concernant la déterminologisation, l'autre la dénominalisation.

Exemple-type (3), sous-corpus 2, Eija

La théorie des graphes est une forme de l'analyse combinatoire.

$\rightarrow$ La théorie des graphes est une forme de l'analyse combinatoire qui exploite des méthodes

de dénombrement.

Dans cet exemple, le scripteur-traducteur reprend son écriture en reformulant sa phrase : il ajoute, dans ce qui a déjà été écrit et sans le modifier, une relative explicative, sans pour autant donc déterminologiser sa toute première formulation, puisque le terme spécialisé de combinatoire est conservé. Il faut noter que la version rédigée en collaboration (version 2a) ne fait aucune mention explicite du terme de combinatoire: l'idée a bien été de déspécialiser l'énoncé en évitant l'utilisation de certains termes. Malgré cela, un groupe d'étudiants maintiendra ce terme. Dans ce groupe, nous trouvons donc des reformulations de la version 1 , de la manière suivante :

Tableau 7. Déterminologisation

\begin{tabular}{|l|l|l|l|}
\hline $\begin{array}{l}\text { Sous- } \\
\text { corpus 2 }\end{array}$ & Réécriture réussie (V2b) & $\begin{array}{l}\text { Opérations } \\
\text { d'écriture }\end{array}$ & $\begin{array}{l}\text { Objet de la } \\
\text { reformulation }\end{array}$ \\
\hline Eija & $\begin{array}{l}\text { [... combinatoire] qui exploite des méthodes de } \\
\text { dénombrement }\end{array}$ & Ajout & $\begin{array}{l}\text { Proposition } \\
\text { relative }\end{array}$ \\
\hline Kaisa & $\begin{array}{l}\text { [... combinatoire], une technique de dénombrement } \\
\text { visant à configurer les combinaisons d'ensembles } \\
\text { possibles, }\end{array}$ & Ajout & $\begin{array}{l}\text { Mise } \\
\text { apposition simple }\end{array}$ \\
\hline Aila & $\begin{array}{l}\text { [... combinatoire }], \text { c'est-à-dire une technique de } \\
\text { dénombrement, }\end{array}$ & Ajout & $\begin{array}{l}\text { Mise } \\
\text { apposition }\end{array}$ \\
\hline
\end{tabular}


Un autre exemple significatif est représenté par la substantivation de l'adjectif. Il est d'usage, en langue de spécialité, de substantiver les adjectifs. On s'attendrait donc à trouver, dans une approche de déterminologisation, des phénomènes inverses, comme en atteste le tableau 8.

Tableau 8. Substantivation

\begin{tabular}{|l|l|l|l|}
\hline $\begin{array}{l}\text { Sous-corpus } \\
2\end{array}$ & Réécriture réussie (V2b) & $\begin{array}{l}\text { Opération } \\
\text { d'écriture }\end{array}$ & $\begin{array}{l}\text { Objet de la } \\
\text { reformulation }\end{array}$ \\
\hline Oili & $\begin{array}{l}\text {.. partie de l'analyse } \\
\text { combinatoire... }\end{array}$ & Ajout & Statut adjectival \\
\hline
\end{tabular}

Dans cet exemple, Oili propose, dans sa première version, la combinatoire pour ensuite procéder à une reformulation par un ajout. Elle propose l'analyse combinatoire, où combinatoire retrouve son statut adjectival. La reformulation par la chaine substantif + adjectif reste plus compréhensible, dans un contexte de déspécialisation, que le seul adjectif substantivé. Il est probable que la reprise faite en cours (version 2a) a eu un réel impact dans la réécriture de tels énoncés. Notons que tous ces ajouts ont été faits sans aucune suppression dans l'environnement immédiat ; ce qui en fait de vrais ajouts.

51 À ce groupe, représentatif d'un comportement limité à peu d'étudiants, correspond un autre groupe d'étudiants pour qui la reprise faite en cours n'a eu aucun impact, voire qu'un impact réduit: Un étudiant ne reformulera pas du tout sa version 1 (Marianna) et deux autres (Elviira \& Karita) se contenteront d'un remplacement simple : ainsi, graphique et graphisme deviendront représentation graphique, expression déjà donnée en cours, dans la version 2a, ce qui représente une réussite modeste.

Exemple-type (4), sous-corpus 4, Aila

[...] en forme graphique qui permet l'illustration du calcul plus effectivement.

$\rightarrow[. .$.$] en forme graphique qui permet de l'illustrer le calcul plus effectivement.$

Cet exemple est représentatif de choix linguistiques propre à une langue de spécialité, où il s'agit de donner priorité à des formulations verbales (tableau 9) :

Tableau 9. Dénominalisation

\begin{tabular}{|l|l|l|l|}
\hline Sous-corpus 4 & Réécriture réussie (V2b) & Opération d'écriture & Objet de la reformulation \\
\hline Aila & permet de l'illustrer le calcul & Remplacement & Dénominalisation \\
\hline
\end{tabular}

Ainsi, Aila a choisi de remplacer le substantif illustration (version 1) par le verbe illustrer dans sa version $2 \mathrm{~b}$. Mais, cette attitude est loin d'être représentative de l'ensemble, puisqu'elle se trouve, encore une fois, être isolée. D'autres étudiants ne chercheront pas à changer les chaines déjà produites : on trouvera ainsi les mêmes formulations dans les deux versions (version 1 et $2 \mathrm{~b}$ ) : capacité d'illustration (Eija), les possibilités illustratives des figures graphiques (Marianna), la possibilité d'illustration offert par la présentation graphique (Elviira) et la possibilité de profiter de la visualisation (Karita). 
D'autres encore accentueront même les chaines de nominalisation produites dans la version première ; ainsi, la possibilité d'illustration d'une représentation graphique deviendra les points variables illustratifs d'une représentation graphique (Kaisa), par une présentation graphique complète va devenir par une illustration de la présentation graphique complète (Soila). Nous sommes loin alors de l'effet recherché.

Mais, ce que cet exemple 4 montre idéalement est que la réécriture n'est pas sans risque : si, d'un côté, l'étudiant a réussi à reformuler son énoncé en remplaçant illustration par illustrer, autrement dit en réussissant à dénominaliser, d'un autre côté, la qualité linguistique de cette reformulation se détériore (de l'illustrer le calcul). Là où, dans la première version, il y avait une formulation conforme à la norme, mais peu souhaitée dans une écriture déspécialisée, on trouve, dans la réécriture (version $2 b$ ), une reformation déspécialisée, mais erronée. Le travail est présent, même si l'issue n'est pas heureuse. Cet énoncé reste, malgré tout, à nos yeux, une réussite qui a été évaluée comme telle.

\subsection{Amélioration versus détérioration}

Si réécrire n'est en rien la garantie d'une amélioration de l'écriture, il n'en reste pas moins vrai, que, sans réécriture, il ne peut y avoir d'améliorations (Cogis \& Leblay, 2011; Cogis, 2013).

D'un côté, à considérer seulement le travail d'écriture réalisé dans la langue commune, il est clair que, d'un point de vue génétique, tout autant que d'un point de vue évaluatif, le travail d'écriture réalisé est presque toujours réussi. Ce qui compte alors est la présence, ou non, d'un travail effectif d'écriture-réécriture. D'un point de vue morphosyntaxique, ce même travail d'écriture ne débouche pas toujours sur une issue heureuse. Le dernier exemple-type peut être caractéristique d'une réécriture qui se détériore, aux yeux de certains enseignants, puisque c'est cette forme qui restera.

D'un autre côté, le travail d'écriture en langue de spécialité se fait conformément à un mandat précis. En examinant les choix faits par nos rédacteurs-traducteurs, nous avons l'impression qu'ils ont voulu intentionnellement faire du sens, pour eux-mêmes, mais aussi pour des lecteurs précis, en essayant de rendre l'information plus lisible. Déspécialiser, c'est écrire-réécrire, traduire donc, pour un lectorat, non spécialiste certes, mais connaisseur, amateur d'un domaine, bien loin d'une production vulgarisée. Nombre d'énoncés correspondent à cette intention d'orienter (version 1), et surtout de réorienter (version $2 b$ ) ce qui a déjà été écrit.

\section{Conclusion}

Arrivés au terme de cet article, nous souhaitons attirer l'attention sur trois aspects qui nous semblent déterminants.

Le tout premier concerne la pertinence de la méthodologie génétique textuelle dans les études de traduction: la génétique affiche clairement, depuis ses principes fondateurs (Grésillon, 1994), des ambitions légitimes dans l'analyse des processus d'écriture (Plane, Alamargot \& Lebrave, 2010). Faut-il voir une influence des principes de la génétique dans la diffusion massive de certains outils d'écriture sur écran (Word offre enfin, par exemple, un onglet spécifique pour la révision)? L'approche génétique, soucieuse de ce qui se passe 
avant la clôture du texte, n'est pas sans lien avec les approches évaluatives qui se préoccupent tout autant de processus. Selon D. Cogis, (2013, p. 105), «l'évaluation de l'écriture reste un processus dynamique qui pose directement la question de la révision ». Réécrire et autoévaluer son écriture ne relèvent donc pas d'actions profondément différentes.

Le deuxième de ces aspects est l'idée que l'écriture traductionnelle reste bien un cas particulier de l'écriture tout court. Ce qui veut dire qu'il est possible de décrire et d'enseigner ce qui est appelé la traduction avec des appareils théoriques et descriptifs identiques à ceux utilisés pour la description et l'enseignement de l'écriture. Dans cet ordre d'idées, nous pensons que la traduction profiterait des méthodologies développées pour la rédaction, et vice-versa.

Enfin, le dernier aspect nous semble concerner directement le mode d'évaluation : il nous semble possible d'évaluer, certains diront corriger, une écriture-réécriture, sans avoir à passer par une évaluation individuelle, copie par copie. Il suffit d'un élément déclencheur, qui est, dans notre cas, l'évaluation coopérative, pour donner l'occasion de faire des retours - majoritairement des remplacements, peu de vrais ajouts, rarement donc des suppressions - sur ce qui a déjà été produit. À la question de savoir si une proposition discutée d'une partie du texte permettait une reformulation réussie de l'ensemble du texte, nous ne pouvons pas encore apporter une réponse tranchée, étant donné la faible représentativité de nos sous-corpus. Néanmoins, ce que nous pouvons souligner est que certains étudiants réagissent très positivement à cette démarche et procèdent à de vraies réécritures réussies.

Ces trois aspects nous amènent vers des questions qui sont tout autant des pistes : a) Que se passe-t-il pendant la discussion commune, pendant cette évaluation coopérative du travail d'écriture? Il serait probablement judicieux de trouver un mode d'enregistrement, audio et/ou vidéo, pour pouvoir déterminer plus précisément si certains éléments (paroles, gestes, situations) ont un impact ou pas. Ce qui nous amènerait vers l'analyse de protocoles verbaux, où il s'agit de faire parler le scripteur pendant ou après son travail d'écriture. b) N'aurait-on pas intérêt de faire travailler les étudiants directement sur écrans afin de sauvegarder plus de données concernant leurs écritures-réécritures traductionnelles? Les approches centrées sur la comparaison de versions, dont le logiciel MEDITE offre un parfait représentant, ne font intervenir l'écran que pour l'analyse : il n'est, en aucun cas, une aide pour l'écriture, ce qui nous semble dommageable, étant donné la diffusion massive des outils numérique d'écriture.

\section{BIBLIOGRAPHIE}

BARBOT, M.-J. (1990). « Métamorphoses de l'évaluation. L'évaluation dans les systèmes d'autoapprentissage ». Études de linguistique appliquée 80, p. 89-112.

CHRISTENSEN, T.P. \& SCHJOLDAGER, A. (2011). « The Impact of Translation Memory (TM) Technology on Cognitive Processes: Student-Translators' Retrospective Comments in an Online 
Questionnaire ». In : Sharp, B., Zock, M., Carl, M. \& Jakobsen, A.L. (éds), Human-machine Interaction in Translation. Freferiksberg: Samfundslitteratur, p. 119-130.

COGIS, D. (2013). « La révision orthographique au CM : l'accord sujet-verbe dans le corpus Grenouille ». In : Gunnarsson-Largy, C. \& Auriac-Slusarczyk, E. (éds), Écriture et réécriture chez les élèves. Un seul corpus, divers genres discursifs et méthodologies d'analyse. Louvain-laNeuve/Paris : Académia-L'Harmattan, p. 89-112.

COGIS, D. \& LEBLAY, C. (2010). « D'un état du texte à l'autre : aperçus sur la révision morphologique en production verbale écrite ». Synergie Pays Scandinaves 5, p. 65-80.

CONDAMINES, A. (2003). Sémantique et corpus spécialisés : Constitution de bases de connaissances terminologiques. Mémoire d'Habilitation à Diriger les Recherches : Université Toulouse 2 Le Mirail. CONDAMINES, A. \& PICTON, A. (2014). « Étude du fonctionnement des nominalisations déverbales dans un contexte de déspécialisation ». SHS Web of Conferences 8, p. 697-711.

DAM-JENSEN, H. \& HEINE, C. (2009). « Process Research Methods and Their Application in the Didactics of Text Production and Translation. Shedding Light on the Use of Research Methods in the University Classroom ». Trans-kom Zeitschrift für Translationswissenschaft und Fachkommunikation 2(1), p. 1-25.

DAM-JENSEN, H. \& HEINE, C. (2013). « Writing and translation process research. Bridging the gap ». Journal of Writing Research 5(1), p. 89-101. En ligne : http://www.jowr.org/articles/vol5_1/ JoWR_2013_vol5_nr1_Dam-Jensen_Heine.pdf.

DRESSEN-HAMMOUDA, D. (2006). «Un défi pour l'enseignement en langue de spécialité : concilier le texte et les besoins de "multimodalité". Recherche et pratiques pédagogiques en langues de spécialité ». Cahiers de l'Apliut 25 (3), p. 60-73.

ELLIS, R. (2005). « Editorial ». Language Teaching Research 9, p. 227-231.

FAYOL, M. (1997). Des idées au texte. Psychologie cognitive de la production verbale, orale et écrite. Paris : Presses universitaires de France.

FENOLGIO, I. \& LREBRAVE, J.-L. \& GANASCIA, J-G. (2007). « EDITE MEDITE : un logiciel de comparaison de versions ». En ligne : http://www.item.ens.fr/index.php?id=172959.

GALISSON, X. (1978). Recherche de lexicologie descriptive, la banalisation lexicale. Paris : Nathan.

GAMBIER, Y. (2012). Traduction: des métiers différents, un processus commun. Département de français, Université de Turku. En ligne : http://www.hum.utu.fi/oppiaineet/ranska/opiskelijavalinta/ valintakoeartikkelit.

GAMBIER, Y. (2017). « Des langues de spécialité aux documents multimodaux ». Pratiques 171-172. En ligne : https://pratiques.revue.org/3155.

GRÉSILLON, A. (1994). Éléments de critique génétique : lire les manuscrits modernes. Paris : Presses universitaires de France.

LEBLANC, R. \& PAINCHAUD, G. (1985). « Self-assessment as a second language placement instrument ». TESOL Quarterly 19(4), p. 673-87.

LEBLAY, C. (2014). « Les écritures intermédiaires réflexives en littératie avancée ». Le français aujourd'hui 184, p. 103-115.

LEBLAY, T. (2013). « Voi ei, nää on tosi hyviä verrattuna muhun! » : uudenlaisen arviointimenetelmän toimivuus ranskan suullisen kielitaidon itsearvioinnissa [ "Oh non, ils sont tellement mieux que moi!» Fonctionnalité d'un système innovant d'évaluation en auto-évaluation - compétence langagière orale, 
français langue étrangère]. Thèse en linguistique appliquée : Université de Jyväskylä. En ligne : https://jyx.jyu.fi/dspace/handle/123456789/42162.

LEE-ELLIS, S. (2009). « The development and validation of a Korean C-Test using Rasch Analysis ». Language Testing 26(2), p. 245-274.

LUCAS U. \& TAN, P. L. (2013). « Developing a capacity to engage in critical reflection: students' "ways of knowing" within an undergraduate business and accounting programme ». Studies in Higher Education 38 (1), p. 104-123.

LUSSIER, D. \& TURNER, C. E. (1995). Le point sur l'évaluation en didactique des langues. Anjou (Québec) : Centre éducatif et culturel Inc.

MEYER, I. \& MACKINTOSH, K. (2000). « "L'étirement" du sens terminologique : aperçu du phonème de la déterminologisation ». In : Béjoint, H. \& Thoiron, P.(éds), Le Sens en terminologie. Lyon : Presses universitaires de Lyon, p. 198-217.

OSCARSON, M. (1997). « Self-assessment of foreign and second language proficiency ». In : Clapham, C. \& Corson, D. (éds), Language Testing and Assessment 7. The encyclopedia of language and education. Dordrecht : Kluwer Academic, p. 175-187.

Plane, S. \& Alamargot, D. \& LebraVe, J.-L. (2010). « Temporalité de l'écriture et rôle du texte produit dans l'activité rédactionnelle ». Langage 177, p. 11-34.

REUTER, Y. (1996). Enseigner et apprendre à écrire. Paris : ESF.

SALMI, L. (2014). « Application aux processus rédactionnels en traduction ». In : Leblay, C. \& Caporossi, G. (éds), Temps de l'écriture. Enregistrements et représentations. Louvain-la-Neuve : Academia-L'Harmattan, p. 193-210.

TRIM, J. T. M. (2007). Les langues vivantes au Conseil de l'Europe 1954-1997. La coopération internationale en faveur de l'apprentissage tout au long de la vie, pour une communication efficace, un enrichissement culturel mutuel et la citoyenneté démocratique en Europe. Le Conseil de l'Europe, Division des politiques linguistiques, Strasbourg.

TSAGARI, D \& FLOROS, G. (2013). Translation in Language Teaching and Assessment. Cambridge : Cambridge Scholars Publishing.

\section{ANNEXES}

\section{Annexe 1. Traduction diplomatique (en finnois) - Domaine de spécialité : Bio-économie}


RANS0033 Traduction en contextes professionnels II, finnois-français

Mandat : Traduisez de l'information spécialisée à destination du grand public (presse)

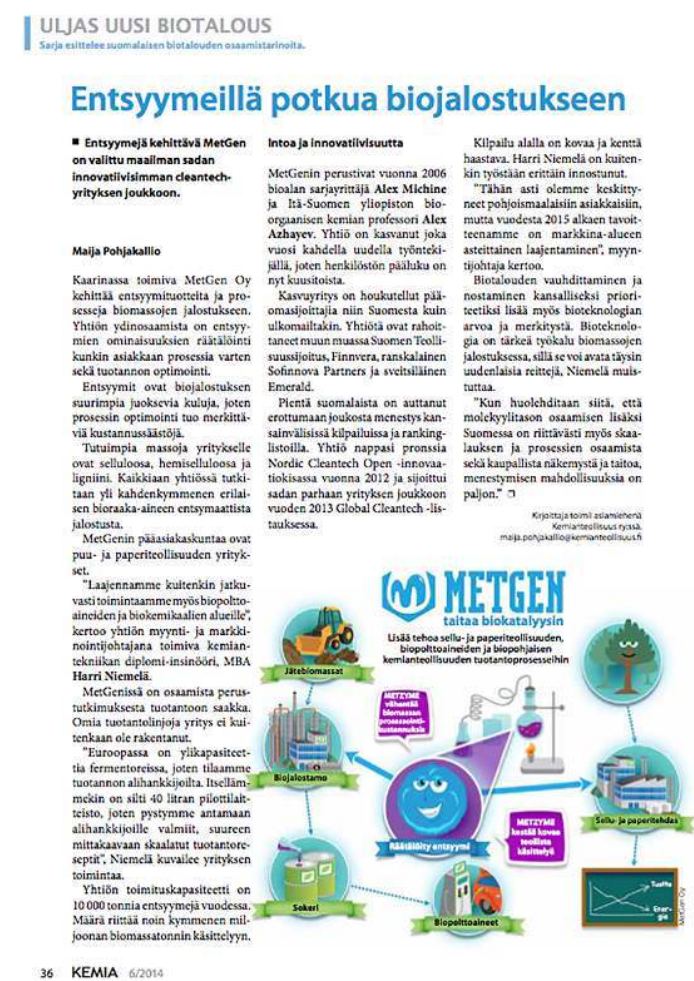

\section{Annexe 2. Traduction linéaire (en finnois) - Domaine de spécialité : Mathématique appliquée}

RANS0033 Traduction en contextes professionnels II, finnois-français

Mandat: Traduisez de l'information spécialisée à destination du grand public (presse)

1. [Eräs graafiteorian käyttötarkoitus on antaa yhtenäinen formalismi lukuisille hyvin erilaisilta näyttäville probleemoille. Algoritmit riittää näin antaa vain tälle yhteiselle formalismille. Tämä on johtanut aivan omaan algoritmiluokkaansa, ns. graafialgoritmeihin. Puolet monisteesta käsitteleekin graafien algoritmeja, jälleen painottaen verkkoteoreettisia menetelmiä. Tässä osuudessa esitetään vain kohtuullisen kokoisiin tehtäviin soveltuvia perusalgoritmeja. Erityisprobleemoihin kuten suurten harvojen graafien käsittelyyn soveltuvia menetelmiä tai rinnakkaisalgoritmeja ei käsitellä, näissä kyse onkin jo paljolti sopivista tietorakenteista (ks. esimerkiksi SKIENA).]

2. Perustaltaan graafiteoria on kombinatoriikkaa, jossa ei sinänsä tarvita "grafiikkaa" muutoin kuin havainnollistamiseen. Graafiteorian sovelluksiin ja mallintamiseen liittyy kuitenkin yleensä tilanteeseen sopivan fysikaalis-geometrisen esityksen antama kontakti "reaalimaailmaan" ja toisaalta kombinatoris-lineaarialgebrallisen koneiston antama matemaattinen määrittely- ja laskukyky.

3. Graafiteorian tulosten ja menetelmien todistuksia ja johtoja ei yleensä esitetä jäykän kombinatorisessa muodossa, vaan käyttäen tehokkaasti hyväksi graafisen esityksen antamaa havainnollistamismahdollisuutta. Tämä voi johtaa tilanteisiin, joissa 
lukijasta ei ehkä tunnu aivan varmalta, että esitetty todistus tai johto olisi täysin sitova. Graafiteorian kurssin yksi tavoite onkin antaa oikeanlainen "tuntuma" graafiteorian esityksiin. Tämä on tarpeen, sillä täysin rigoristinen matemaattinen esitys on usein myös melkein täysin lukukelvoton, löysä ja aukkoinen esitys taas käyttökelvoton. (s. ii)

Ruohonen, K. 2013. Graafiteoria. TTY:n kurssin "MAT-62756 Graph Theory. Moniste.

Questions :

Identifiez le domaine \& la langue de spécialité aussi précisément que possible :

a. Comment fonctionne la terminologisation du texte? Donnez des expressions spécialisées significatives de la langue source?

b. Recherche documentaire (documents utilisés, les 4 principaux) :

c. Traduisez les paragraphes 2 \& 3(attention aux phénomènes déviants et aux attendus) :

\section{Annexe 3. Sous-corpus - Domaines de spécialité : Bioéconomie \& Mathématique appliqué}

Tableau 10. Sous-corpus - domaine de spécialité : Bioéconomie

\begin{tabular}{|c|c|c|c|c|}
\hline $\begin{array}{l}\text { Sous-corpus } \\
\text { aligné } \\
\text { (Texte source en } \\
\text { finnois) } \\
\text { Domaine: } \\
\text { Bioéconomie }\end{array}$ & $\begin{array}{l}\text { Scripteur- } \\
\text { traducteur }\end{array}$ & $\begin{array}{l}\text { Version } 1 . \\
\text { Réalisée en travail } \\
\text { autonome }\end{array}$ & $\begin{array}{l}\text { Version } 2 \mathrm{a} . \\
\text { Réalisée } \\
\text { collaboration } \\
\text { Etudiants- } \\
\text { enseignant }\end{array}$ & $\begin{array}{l}\text { Version } 2 \mathrm{~b} . \\
\text { Réalisée en travail } \\
\text { autonome }\end{array}$ \\
\hline $\begin{array}{l}\text { Entsyymejä } \\
\text { kehittävä MetGen } \\
\text { on valittu } \\
\text { maailman sadan } \\
\text { innovatiivisimman } \\
\text { cleantech- } \\
\text { yrityksen }\end{array}$ & Eija & $\begin{array}{l}\text { MetGen, innovateur } \\
\text { de la production des } \\
\text { enzymes, a été } \\
\text { choisi parmi les } 100 \\
\text { entreprises cleantech } \\
\text { les plus innovantes } \\
\text { en monde entier. }\end{array}$ & $\begin{array}{l}\text { L'entreprise } \\
\text { finlandaise MetGen, } \\
\text { spécialisée dans la } \\
\text { production } \\
\text { d'enzymes, a été } \\
\text { sélectionnée parmi } \\
\text { les } 100 \text { entreprises }\end{array}$ & $\begin{array}{l}\text { MetGen, innovateur de } \\
\text { production } \\
\text { enzymes, a été choisi } \\
\text { parmi les } 100 \\
\text { entreprises cleantech } \\
\text { les plus innovante au } \\
\text { monde. }\end{array}$ \\
\hline & & & $\begin{array}{l}\text { cleantech les plus } \\
\text { innovatrices au } \\
\text { monde. }\end{array}$ & \\
\hline
\end{tabular}




\begin{tabular}{|c|c|}
\hline Kaisa & $\begin{array}{l}\text { L'entreprise } \\
\text { MetGenon, active } \\
\text { dans la production } \\
\text { des enzymes, a été } \\
\text { introduit parmi les } \\
\text { entreprises de } \\
\text { technologies propes } \\
\text { les plus novatrices. }\end{array}$ \\
\hline Aila & $\begin{array}{l}\text { MetGen, } \\
\text { entreprise } \\
\text { finlandaise } \\
\text { spécialisé dans le } \\
\text { production des } \\
\text { enzymes, a été } \\
\text { nommée entre les } \\
100 \text { entreprises les } \\
\text { plus innovatrices du } \\
\text { domaine } \\
\text { cleantech. }\end{array}$ \\
\hline Soila & $\begin{array}{l}\text { La r compagnie } \\
\text { MetGem, connue } \\
\text { pour re } \\
\text { développement des } \\
\text { enzymes, fait partie } \\
\text { de cents autres } \\
\text { compagnies } \\
\text { "cleantech » la plus } \\
\text { innovatrice r au } \\
\text { monde }\end{array}$ \\
\hline Marianna & $\begin{array}{l}\text { L'entreprise } \\
\text { MetGen, } \\
\text { développant les } \\
\text { enzymes, a affermit } \\
\text { son statut } \\
\text { aujourd'hui parmi } \\
\text { centaines } \\
\text { d'entreprises } \\
\text { innovatives, c'est-à- } \\
\text { dire, les entreprises } \\
\text { Cleantech. }\end{array}$ \\
\hline
\end{tabular}

L'entreprise

finlandaise MetGen,

active dans la

production des

enzymes, a été

introduite parmi les

100 entreprises de

technologies propres

les plus novatrices au

monde.

L'entreprise

finlandaise MetGen, spécialisée dans la production

d'enzymes, a été sélectionnée parmi les 100 entreprises cleantech les plus innovatrices au monde.

La compagnie MetGen, connue pour le développement d'enzymes,

fait partie de cents autres compagnies cleantech

la plus innovatrice au monde.

L'entreprise MetGen, spécialisée dans la production

d'enzymes, a été sélectionnée parmi les 100 entreprises cleantech les plus innovatrices au monde. 


\begin{tabular}{|c|c|c|}
\hline Elviira & 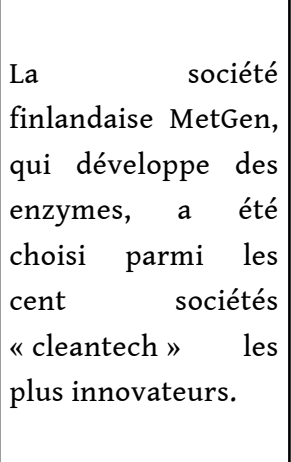 & $\begin{array}{l}\text { L'entreprise } \\
\text { finlandaise MetGen, } \\
\text { spécialisée dans la } \\
\text { production } \\
\text { d'enzymes, a été } \\
\text { sélectionnée parmi } \\
\text { les } 100 \text { entreprises } \\
\text { cleantech les plus } \\
\text { innovatrices au } \\
\text { monde. }\end{array}$ \\
\hline Karita & - & - \\
\hline Nina & $\begin{array}{l}\text { La société de } \\
\text { développement } \\
\text { d'enzymes MetGen a } \\
\text { été choisie parmi les } \\
\text { cent entreprises } \\
\text { cleantech (éco- } \\
\text { technologies) les } \\
\text { plus innovatrices. }\end{array}$ & $\begin{array}{l}\text { La société de } \\
\text { développement } \\
\text { d'enzymes MetGen a } \\
\text { été choisie parmi les } \\
\text { cent entreprises } \\
\text { cleantech (éco- } \\
\text { technologiques) les } \\
\text { plus innovatrices. }\end{array}$ \\
\hline Isa & 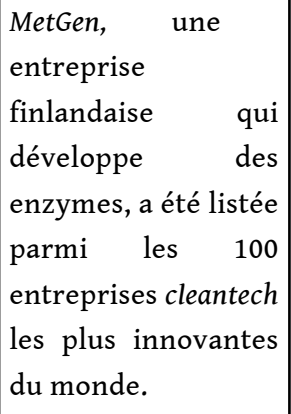 & $\begin{array}{l}\text { MetGen, une } \\
\text { entreprise finlandaise } \\
\text { qui développe des } \\
\text { enzymes, a été listée } \\
\text { parmi les } 100 \\
\text { entreprises cleantech } \\
\text { les plus innovantes } \\
\text { du monde. }\end{array}$ \\
\hline Oili & $\begin{array}{lr}\text { Dans la } & \text { sélection } \\
\text { des } & \text { cent } \\
\text { entreprises } & \text { plus } \\
\text { innovantes dans le } \\
\text { secteur } & \text { de } \\
\text { cleantech, } & \text { c'est } \\
\text { MetGen, } & \text { une } \\
\text { entreprise } & \\
\text { finlandaise, } & \text { qui } \\
\text { développe } & \text { des } \\
\text { enzymes. } & \end{array}$ & $\begin{array}{l}\text { La société de } \\
\text { développement } \\
\text { d'enzyme MetGen a } \\
\text { été choisie parmi les } \\
\text { cent entreprises } \\
\text { cleantech (éco- } \\
\text { technologies) les } \\
\text { plus innovatrices. }\end{array}$ \\
\hline
\end{tabular}


Tableau 11. Sous-corpus - domaine de spécialité : Mathématique appliquée, théorie des graphes1

\begin{tabular}{|c|c|c|c|c|}
\hline $\begin{array}{ll}\text { Sous-corpus } & 2 \\
\text { aligné } & \\
\text { (Texte source en } \\
\text { finnois) } \\
\text { Domaine: } \\
\text { Mathématique }\end{array}$ & $\begin{array}{l}\text { Scripteur- } \\
\text { traducteur }\end{array}$ & $\begin{array}{l}\text { Version } 1 . \\
\text { Réalisée } \\
\text { travail } \\
\text { autonome }\end{array}$ & $\begin{array}{l}\text { Version 2a. } \\
\text { Réalisée } \\
\text { collaboration } \\
\text { Etudiants-enseignant }\end{array}$ & $\begin{array}{l}\text { Version } 2 \mathrm{~b} . \\
\text { Réalisée } \\
\text { travail autonome }\end{array}$ \\
\hline \multirow[t]{2}{*}{$\begin{array}{l}\text { Perustaltaan } \\
\text { graafiteoria on } \\
\text { kombinatoriikkaa, } \\
\text { jossa ei sinänsä } \\
\text { tarvita "grafiikkaa" } \\
\text { muutoin kuin } \\
\text { havainnollistamiseen. }\end{array}$} & Eija & $\mid \begin{array}{lr}\text { La théorie des } \\
\text { graphes est une } \\
\text { forme } \\
\text { l'analyse } \\
\text { combinatoire. }\end{array}$ & \multirow[t]{2}{*}{$\begin{array}{l}\text { La théorie des graphes est } \\
\text { basée sur la technique de } \\
\text { dénombrement où la } \\
\text { représentation graphique } \\
\text { n'a qu'une fonction } \\
\text { illustrative. }\end{array}$} & $\begin{array}{lr}\text { La théorie des } \\
\text { graphes est } \\
\text { forme } \\
\text { l'analyse } \\
\text { combinatoire qui } \\
\text { exploiter des } \\
\text { méthodes de } \\
\text { dénombrement. }\end{array}$ \\
\hline & Kaisa & 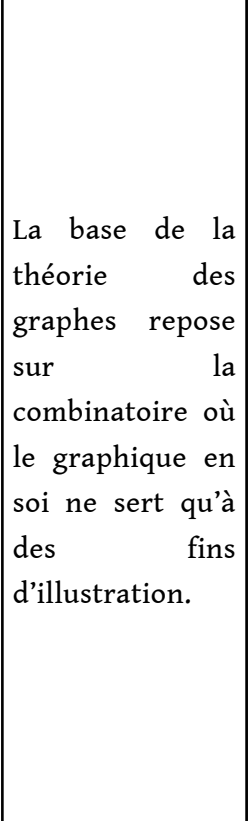 & & $\begin{array}{l}\text { La base de la } \\
\text { théorie des } \\
\text { graphes repose } \\
\text { sur l'analyse } \\
\text { combinatoire, } \\
\text { une technique de } \\
\text { dénombrement } \\
\text { visant à } \\
\text { configurer les } \\
\text { combinaisons } \\
\text { d'ensembles } \\
\text { possibles, où «la } \\
\text { représentation } \\
\text { graphique en en } \\
\text { soi n'a pour } \\
\text { fonction que de } \\
\text { concrétiser le } \\
\text { calcul. }\end{array}$ \\
\hline
\end{tabular}




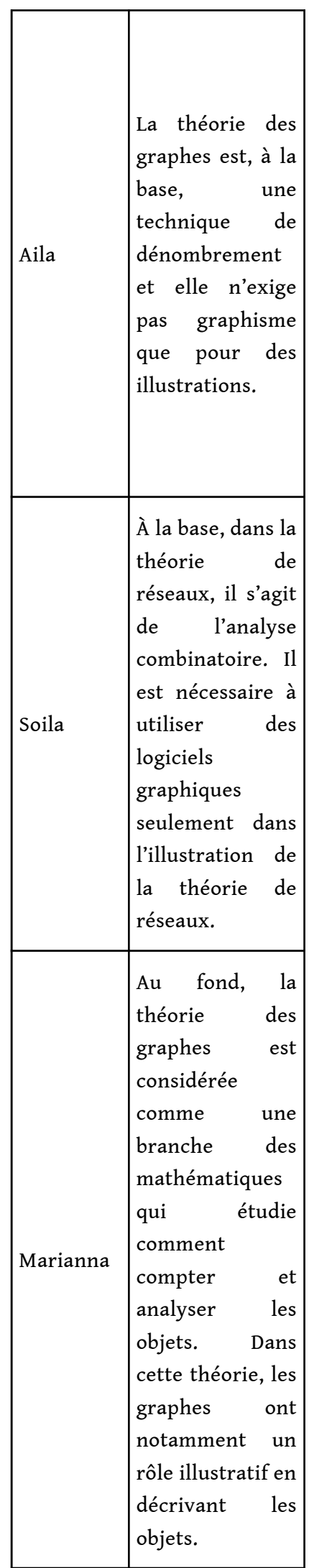

La théorie des graphes est, à la base, d'analyse combinatoire, c'est-à-dire une technique de dénombrement, et représentation graphique » n'est vraiment utilisée que pour concrétiser le calcul.

La théorie de graphes s'est basée sur l'analyse combinatoire. Il est nécessaire à utiliser des logiciels graphiques que dans

l'illustration de la théorie de réseaux.

$\mathrm{Au}$ fond, la théorie des graphes est considérée comme une branche des mathématiques qui étudie comment compter analyser des objets. Dans cette théorie, les graphes ont notamment un rôle illustratif en décrivant les objets. 


\begin{tabular}{|c|c|}
\hline Elviira & $\begin{array}{l}\text { La théorie des } \\
\text { graphes s'est } \\
\text { basée sur } \\
\text { l'analyse } \\
\text { combinatoire où } \\
\text { la "graphique" } \\
\text { n'est vraiment } \\
\text { utilisée que pour } \\
\text { l'illustration. }\end{array}$ \\
\hline Karita & $\begin{array}{ll}\text { La base de la } & \text { théorie des } \\
\text { graphes est } \\
\text { l'analyse } \\
\text { combinatoire, } \\
\text { qui calcule et } \\
\text { examine } \\
\text { combien de } \\
\text { façons } \\
\text { différentes on } \\
\text { peut compter les } \\
\text { arrangements } \\
\text { possibles des } \\
\text { objets. On utilise } \\
\text { actuellement le } \\
\text { "graphisme" } \\
\text { seulement pour } \\
\text { concrétiser le } \\
\text { calcul. }\end{array}$ \\
\hline Nina & $\begin{array}{l}\text { De la base, la } \\
\text { théorie des } \\
\text { graphes est } \\
\text { d'analyse } \\
\text { combinatoire (la } \\
\text { combinatoire } \\
\text { étudie les } \\
\text { configurations } \\
\text { de collections } \\
\text { finies d'objets) } \\
\text { qui n'a pas } \\
\text { forcément } \\
\text { besoin de la } \\
\text { graphique pour } \\
\text { d'autre fonction } \\
\text { que rion. } \\
\text { l'illustration. }\end{array}$ \\
\hline
\end{tabular}

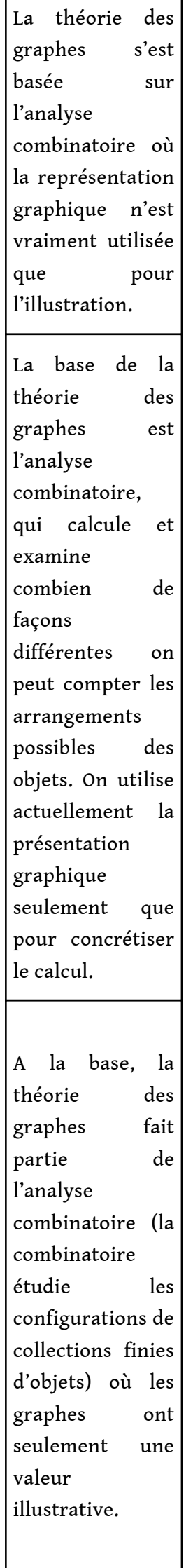




\begin{tabular}{|c|c|c|}
\hline 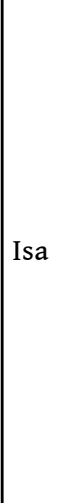 & $\begin{array}{lr}\text { A la base, la } \\
\text { théorie res } \\
\text { graphes r fait } \\
\text { partie de la } \\
\text { combinatoire, } \\
\text { qui nécessite du } \\
\text { graphisme } \\
\text { seulement pour } \\
\text { l'illustration. }\end{array}$ & $\begin{array}{lr}\text { À la base, la } \\
\text { théorie des } \\
\text { graphes fait } \\
\text { partie de } \\
\text { l'analyser } \\
\text { combinatoire, } \\
\text { qui ne nécessite } \\
\text { pas de graphique } \\
\text { pour d'autre } \\
\text { fonction que } \\
\text { l'illustration. }\end{array}$ \\
\hline Oili & $\begin{array}{l}\text { La base de la } \\
\text { théorie des } \\
\text { graphes est dans } \\
\text { la combinatoire, } \\
\text { où la graphique } \\
\text { fait seulement la } \\
\text { partie pour la } \\
\text { démonstration. }\end{array}$ & $\begin{array}{l}\text { La base de la } \\
\text { théorie des } \\
\text { graphes est de } \\
\text { l'analyse } \\
\text { combinatoire, où } \\
\text { les graphes ont } \\
\text { seulement une } \\
\text { valeur } \\
\text { démonstrative. }\end{array}$ \\
\hline
\end{tabular}

Tableau 12. Sous-corpus - domaine de spécialité : Mathématique appliquée, théorie des graphes2

\begin{tabular}{|l|l|l|l|l|}
\hline $\begin{array}{l}\text { Sous-corpus 3 aligné } \\
\text { (Texte source en } \\
\text { finnois) } \\
\begin{array}{l}\text { Domaine : } \\
\text { Mathématique }\end{array}\end{array}$ & $\begin{array}{l}\text { Scripteur- } \\
\text { traducteur }\end{array}$ & $\begin{array}{l}\text { Version 1. } \\
\text { Réalisée en travail } \\
\text { autonome }\end{array}$ & $\begin{array}{l}\text { Réalisée en } \\
\text { collaboration } \\
\text { Etudiants- } \\
\text { enseignant }\end{array}$ & $\begin{array}{l}\text { Version 2b. } \\
\text { Réalisée en } \\
\text { travail autonome }\end{array}$ \\
\hline
\end{tabular}




\begin{tabular}{|c|c|c|c|c|}
\hline \multirow[t]{2}{*}{$\begin{array}{l}\text { Graafiteorian } \\
\text { sovelluksiin ja } \\
\text { mallintamiseen } \\
\text { liittyy kuitenkin } \\
\text { yleensä tilanteeseen } \\
\text { sopivan fysikaalis- } \\
\text { geometrisen } \\
\text { esityksen antama } \\
\text { kontakti } \\
\text { "reaalimaailmaan" ja } \\
\text { toisaalta } \\
\text { kombinatoris- } \\
\text { lineaarialgebrallisen } \\
\text { koneiston antama } \\
\text { matemaattinen } \\
\text { määrittely- } \\
\text { laskukyky. ja }\end{array}$} & Eija & $\begin{array}{l}\text { Quand on applique ou } \\
\text { modèle la théorie des } \\
\text { graphes, en général les } \\
\text { formules de physique } \\
\text { et de géométrie créent } \\
\text { un contact avec le } \\
\text { monde réel, tandis que } \\
\text { les formules d'analyse } \\
\text { combinatoire et } \\
\text { d'algèbre linéaire lui } \\
\text { donnent la capacité } \\
\text { mathématique de faire } \\
\text { des définitions et des } \\
\text { calculs. }\end{array}$ & $\begin{array}{l}\text { Cependant, les } \\
\text { applications et } \\
\text { la modélisation } \\
\text { de la théorie } \\
\text { des graphes } \\
\text { sont } \\
\text { généralement } \\
\text { associées au } \\
\text { contact réel } \\
\text { établi par une } \\
\text { représentation } \\
\text { physico- } \\
\text { géométrique } \\
\text { convenant/ } \\
\text { adaptée à une } \\
\text { situation et, } \\
\text { d'autre part, à } \\
\text { l'aptitude } \\
\text { mathématique } \\
\text { à déterminer et } \\
\text { à compter } \\
\text { fourni par un } \\
\text { *système }\end{array}$ & $\begin{array}{l}\text { L'emploi de la } \\
\text { théorie des } \\
\text { graphes est à la } \\
\text { fois pratique et } \\
\text { théorique; les } \\
\text { formules de } \\
\text { physique et de } \\
\text { géométrie créent } \\
\text { un contact le } \\
\text { plus proche } \\
\text { possible avec le } \\
\text { monde réel, } \\
\text { tandis que les } \\
\text { formules } \\
\text { d'analyse } \\
\text { combinatoire et } \\
\text { d'algèbre lui } \\
\text { donnent } \\
\text { capacité } \\
\text { mathématique } \\
\text { de faire des } \\
\text { définitions et des } \\
\text { calculs. }\end{array}$ \\
\hline & Kaisa & $\begin{array}{l}\text { les } \\
\text { Cependant, la } \\
\text { applications et la } \\
\text { modélisation de la } \\
\text { théorie ánt } \\
\text { généralement associées } \\
\text { au contact réel établi } \\
\text { par une représentation } \\
\text { physico-géométrique } \\
\text { convenant à la } \\
\text { situation et d'autre } \\
\text { part à l'aptitude } \\
\text { mathématique à } \\
\text { déterminer et à } \\
\text { compter fournie par un } \\
\text { système combinatoire } \\
\text { algébrique linéaire. }\end{array}$ & $\begin{array}{l}\text { Algébrique } \\
\text { linéaire*. }\end{array}$ & $\begin{array}{l}\text { Cependant, les } \\
\text { applications et la } \\
\text { modélisation de } \\
\text { la théorie des } \\
\text { graphes sont } \\
\text { généralement } \\
\text { associées au } \\
\text { "contact réel " } \\
\text { établi par une } \\
\text { représentation } \\
\text { physico- } \\
\text { géométrique } \\
\text { convenant à une } \\
\text { situation et, } \\
\text { d'autre part, à } \\
\text { l'aptitude } \\
\text { mathématique à } \\
\text { déterminer et à } \\
\text { compter fournie } \\
\text { par des aspects } \\
\text { algébriques } \\
\text { linéaires du } \\
\text { système } \\
\text { combinatoire. }\end{array}$ \\
\hline
\end{tabular}


Pourtant, il existe normalement un lien entre le monde concret et les applications et les modèles de la théorie des graphes. Ce lien est créé par des représentations

Aila géométriques physiques appropriées à la situation. Également, ces applications et modèles sont liées, en général, aux définitions et aux calculs mathématiques d'algèbre linéaire et combinatoire.

Quant aux applications et à la modélisation de la théorie de réseaux, d'une part, une présentation physique et géométrique illustre Soila du monde réel. D’autre part, une formule de la combinatoire et de l'algèbre linéaire montre l'aptitude au calcul et l'aptitude à la définition.
Pourtant, existe normalement un lien entre le monde concret et applications et les modèles de la théorie des graphes. Ce lien est créé par des représentations géométriques et physiques appropriées à une situation. Également, ces applications et modèles sont liées définitions et aux calculs mathématiques d'algèbre linéaire combinatoire.

Les applications et modélisation de la théorie de réseaux, d'une part est lié à une présentation physicogéométrique illustrant du monde réel, et d'autre part, une formule de la combinatoire et de l'algèbre linéaire montre l'aptitude au calcul et à la définition mathématique. 


\begin{tabular}{|c|c|c|}
\hline Marianna & 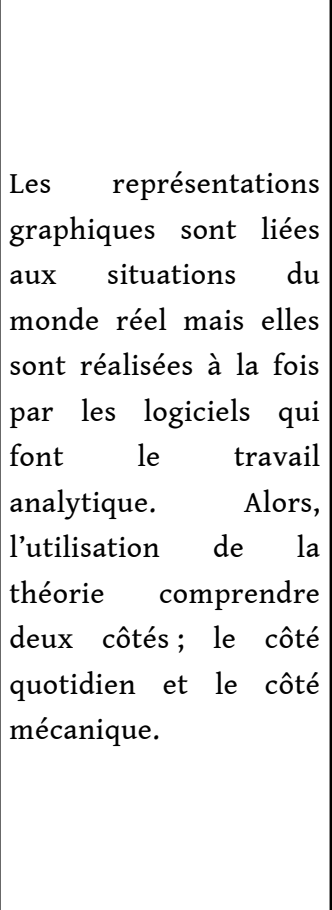 & 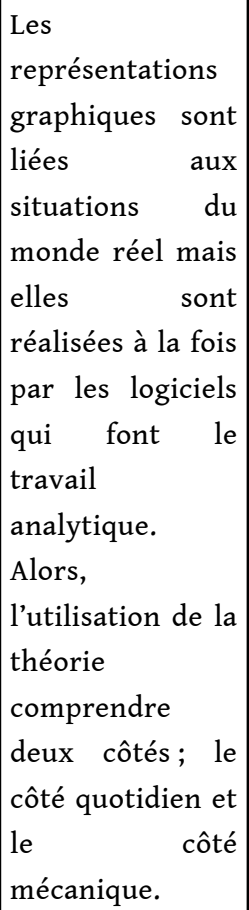 \\
\hline Elviira & 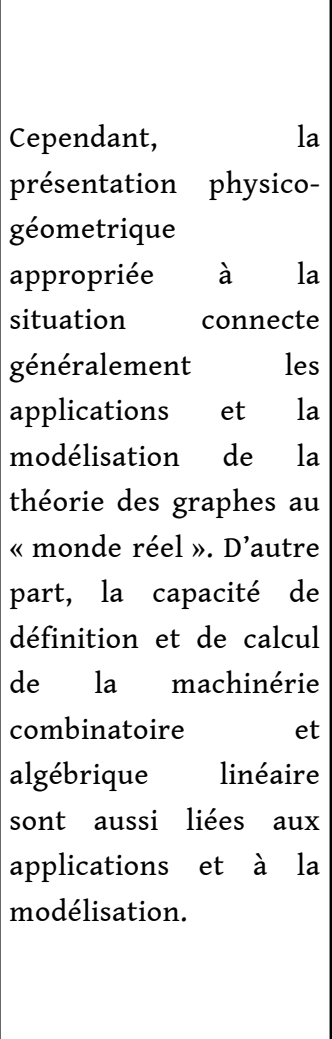 & 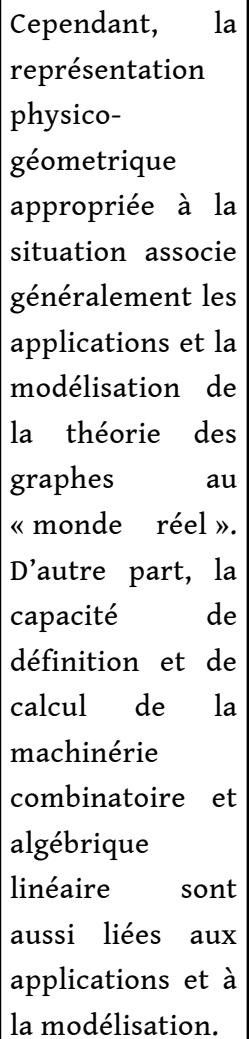 \\
\hline
\end{tabular}




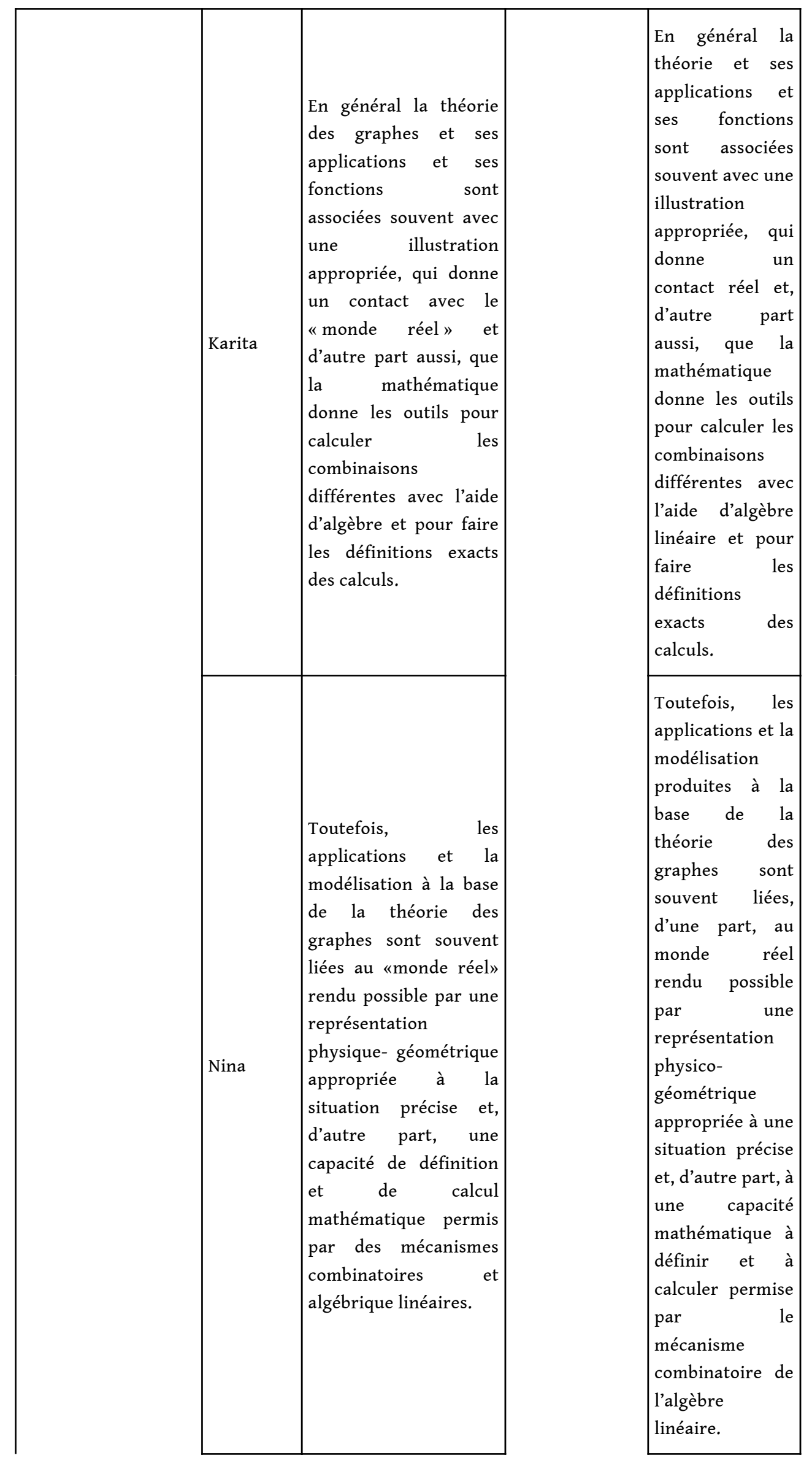


Pourtant, l'application et la modélisation de la théorie des graphes contiennent souvent, d'une part, le contact au monde réel donné par la présentation physico-géométrique, et d'autre part, la capacité mathématique de définir et de calculer donnée par l'appareil (kombinatorislineaarialgebrallinen).

Oili
L'application et la modélisation de la théorie des graphes sont généralement liés avec la présentation physico-géométrique, qui donne la contacte dans le monde réel, et d'autre part avec les capacités

mathématiques de la définition et le calcul donnes par le mécanisme combinatoire de l'algèbre linéaire.
Toutefois, les applications et la modélisation produites à la base de la théorie des graphes sont souvent liées, d'une part, au monde réel rendu possible par une représentation physicogéométrique appropriée à une situation précise et, d'autre part, à une capacité mathématique à définir et à calculer offerte par

mécanismes

combinatoires et algébriques linéaires.

Toutefois, les applications et la modélisation produites à la base de la théorie des graphes sont souvent liées, d'une part, au monde réel rendu possible par une représentation physicogéométrique et, d'autre part, à la capacité

mathématique à définir et à calculer offerte par mécanisme combinatoire de l'algèbre linéaire. 
Tableau 13. Sous-corpus - domaine de spécialité : mathématique appliquée, théorie des graphes3

\begin{tabular}{|c|c|c|c|c|}
\hline $\begin{array}{l}\text { Sous-corpus } 4 \text { aligné } \\
\text { (en finnois) } \\
\text { Domaine : Mathématique }\end{array}$ & $\begin{array}{l}\text { Scripteur- } \\
\text { traducteur }\end{array}$ & $\begin{array}{l}\text { Version } 1 . \\
\text { Réalisée } \\
\text { travail } \\
\text { autonome }\end{array}$ & $\begin{array}{l}\text { Version 2a. } \\
\text { Réalisée en } \\
\text { collaboration } \\
\text { Etudiants- } \\
\text { enseignant }\end{array}$ & $\begin{array}{l}\text { Version } 2 \mathrm{~b} . \\
\text { Réalisée en } \\
\text { travail } \\
\text { autonome }\end{array}$ \\
\hline \multirow[t]{2}{*}{$\begin{array}{l}\text { Graafiteorian tulosten ja } \\
\text { menetelmien todistuksia ja } \\
\text { johtoja ei yleensä esitetä jäykän } \\
\text { kombinatorisessa muodossa, } \\
\text { vaan käyttäen tehokkaasti } \\
\text { hyväksi graafisen esityksen } \\
\text { antamaa } \\
\text { havainnollistamismahdollisuutta. }\end{array}$} & Eija & $\begin{array}{l}\text { En théorie des } \\
\text { graphes, la } \\
\text { démonstration } \\
\text { des résultats et } \\
\text { des methodes } \\
\text { n'est pas } \\
\text { généralement } \\
\text { présentée } \\
\text { strictement et } \\
\text { théoriquement, } \\
\text { mais en } \\
\text { profitant de } \\
\text { présentation } \\
\text { graphique et sa } \\
\text { capacité } \\
\text { d'illustration. }\end{array}$ & \multirow[t]{2}{*}{$\begin{array}{l}\text { Ses objets et } \\
\text { ses résultats } \\
\text { ne sont pas } \\
\text { représentés } \\
\text { d'une façon } \\
\text { rigide mais } \\
\text { en profitant } \\
\text { des } \\
\text { possibilités } \\
\text { illustratives } \\
\text { des figures } \\
\text { graphiques. }\end{array}$} & $\begin{array}{l}\text { Le calcul et } \\
\text { son résultat ne } \\
\text { sont pas } \\
\text { présentés } \\
\text { seulement en } \\
\text { chiffres, mais } \\
\text { en profitant de } \\
\text { figures } \\
\text { graphiques et } \\
\text { leur capacité } \\
\text { d'illustration. }\end{array}$ \\
\hline & Kaisa & $\begin{array}{l}\text { En général, les } \\
\text { preuves et les } \\
\text { dérivés de } \\
\text { résultats et de } \\
\text { méthodes de la } \\
\text { théorie des } \\
\text { graphes ne sont } \\
\text { pas présentés } \\
\text { sous forme } \\
\text { combinatoire } \\
\text { rigide, au } \\
\text { contraire, cela } \\
\text { se fait en } \\
\text { exploitant } \\
\text { efficacement la } \\
\text { possibilité } \\
\text { d'illustration } \\
\text { d'une } \\
\text { représentation } \\
\text { graphique. }\end{array}$ & & $\begin{array}{l}\text { En général, les } \\
\text { preuves et les } \\
\text { objets de } \\
\text { résultats et de } \\
\text { méthodes ne } \\
\text { sont pas } \\
\text { représentés } \\
\text { sous une } \\
\text { forme rigide } \\
\text { typique de } \\
\text { combinatoire, } \\
\text { au contraire, } \\
\text { cela se fait en } \\
\text { exploitant } \\
\text { efficacement } \\
\text { les points } \\
\text { variables } \\
\text { illustratifs } \\
\text { d'une } \\
\text { représentation } \\
\text { graphique. }\end{array}$ \\
\hline
\end{tabular}




\begin{tabular}{|c|c|}
\hline Aila & $\begin{array}{l}\text { Au lieu de les } \\
\text { présenter sous } \\
\text { la forme } \\
\text { combinatoire } \\
\text { rigide, les } \\
\text { démonstrations } \\
\text { et les dérivés } \\
\text { des méthodes et } \\
\text { des sommes de } \\
\text { la théorie des } \\
\text { graphes sont } \\
\text { normalement } \\
\text { en forme } \\
\text { graphique qui } \\
\text { permet l'illustration du } \\
\text { calcul plus } \\
\text { effectivement. }\end{array}$ \\
\hline Soila & $\begin{array}{l}\text { Les résultats de } \\
\text { preuves et de } \\
\text { méthodes de la } \\
\text { théorie de } \\
\text { réseaux ne sont } \\
\text { pas représentés } \\
\text { par l'analyse } \\
\text { combinatoire } \\
\text { stricte. Ils sont } \\
\text { illustrés par } \\
\text { une } \\
\text { présentation } \\
\text { graphique } \\
\text { complète. }\end{array}$ \\
\hline Marianna & $\begin{array}{l}\text { Les objets et } \\
\text { résultats ne } \\
\text { sont pas } \\
\text { représentés } \\
\text { d'une façon } \\
\text { rigide mais en } \\
\text { profitant les } \\
\text { possibilités } \\
\text { illustratives des } \\
\text { figures } \\
\text { graphiques. }\end{array}$ \\
\hline
\end{tabular}

$\mathrm{Au}$ lieu de les présenter sous la forme combinatoire rigide, les résultats et les preuves des procédures et des sommes de cette théorie sont normalement en forme graphique qui permet de l'illustrer le calcul plus effectivement.

Les résultats de preuves et de méthodes de la théorie de réseaux ne sont pas représentés par une façon rigide, mais par une illustration de la présentation graphique complète.

Ses objets et ses résultats ne sont pas représentés d'une façon rigide mais en profitant les possibilités illustratives des figures graphiques. 


\begin{tabular}{|c|c|}
\hline Elviira & $\begin{array}{l}\text { Généralement, } \\
\text { les preuves et } \\
\text { les conclusions } \\
\text { des résultats et } \\
\text { des méthodes } \\
\text { de la théorie } \\
\text { des graphes ne } \\
\text { sont pas } \\
\text { présentées dans } \\
\text { une forme } \\
\text { combinatoire } \\
\text { stricte, mais } \\
\text { dans une forme } \\
\text { qui profite } \\
\text { effectivement } \\
\text { de la possibilité } \\
\text { d'illustration } \\
\text { offert par la } \\
\text { présentation } \\
\text { graphique. }\end{array}$ \\
\hline Karita & $\begin{array}{l}\text { Les résultats, } \\
\text { les preuves des } \\
\text { procédures et } \\
\text { les conductions } \\
\text { de la théorie } \\
\text { des graphes ne } \\
\text { sont pas } \\
\text { présentés } \\
\text { seulement en } \\
\text { strict forme } \\
\text { combinatoire, } \\
\text { mais utilisant la } \\
\text { possibilité de } \\
\text { profiter de la } \\
\text { visualisation. }\end{array}$ \\
\hline
\end{tabular}

Généralement, les preuves et les conclusions des résultats et des méthodes de la théorie des graphes ne sont représentées d'une manière rigide, mais dans une forme qui profite effectivement de possibilité d'illustration offert par la présentation graphique.

Ses résultats, ses preuves des procédures et conductions ne sont pas présentés seulement en strict forme combinatoire, mais utilisant la possibilité de profiter de la

visualisation. 


\begin{tabular}{|c|c|}
\hline Nina & $\begin{array}{l}\text { Les certificats } \\
\text { et les conduits } \\
\text { des résultats et } \\
\text { des méthodes } \\
\text { de la théorie } \\
\text { des graphes } \\
\text { n'est sont pas } \\
\text { généralement } \\
\text { présentés sous } \\
\text { la forme } \\
\text { combinatoire } \\
\text { rigide mais en } \\
\text { utilisant une } \\
\text { représentation } \\
\text { graphique pour } \\
\text { concrétiser la } \\
\text { présentation de } \\
\text { la façon } \\
\text { efficace. }\end{array}$ \\
\hline Isa & 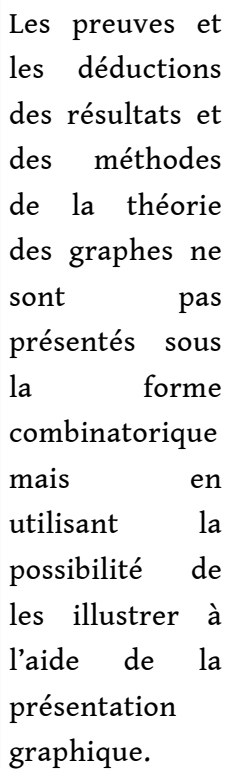 \\
\hline
\end{tabular}

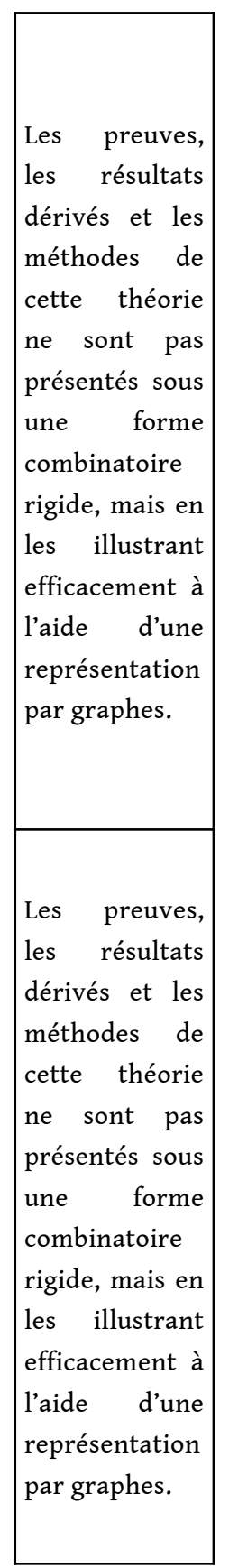




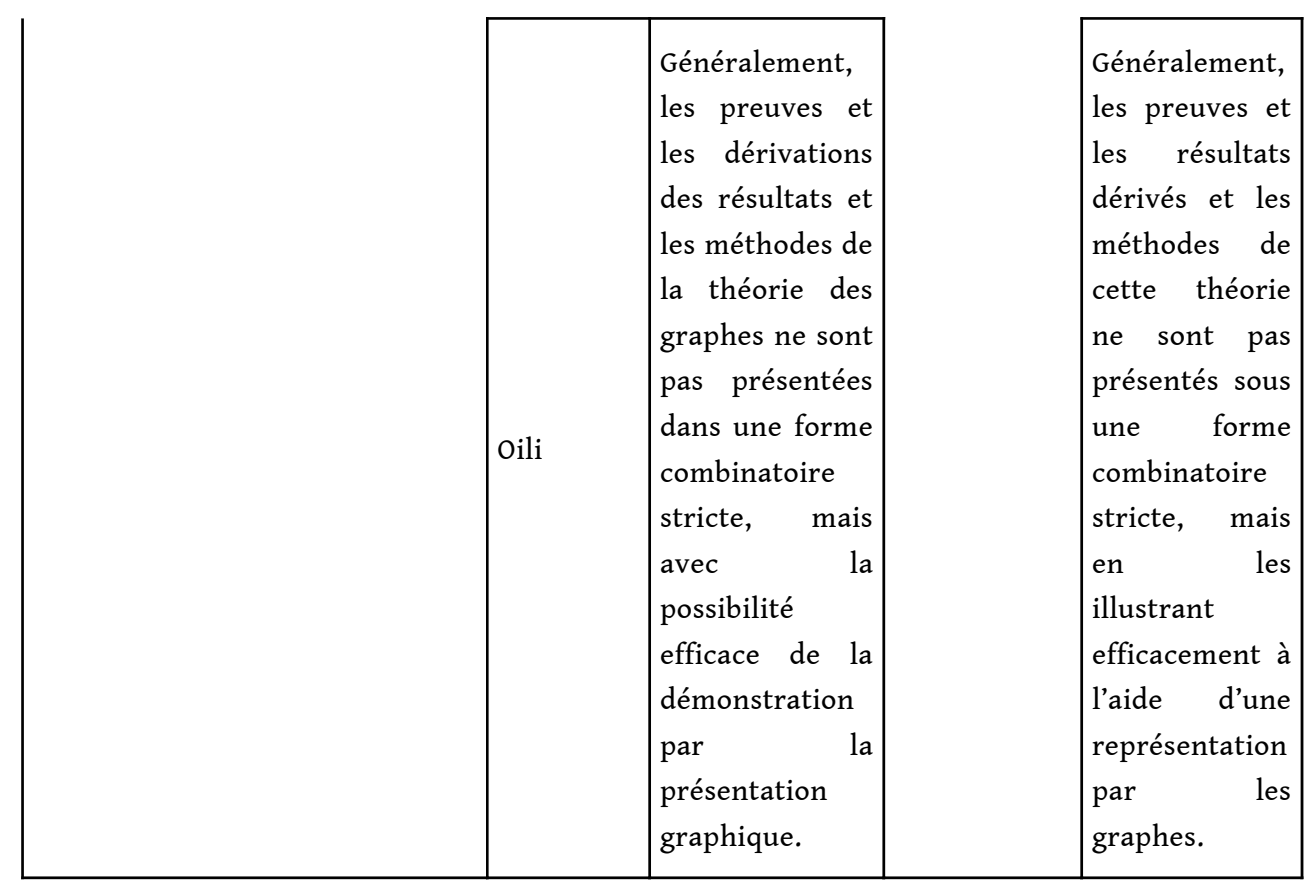

\section{Annexe 4. MEDITE}

Saisies d'écran de comparaisons entre deux versions, réalisée sur le logiciel MEDITE.

\section{Exemple-type 1}

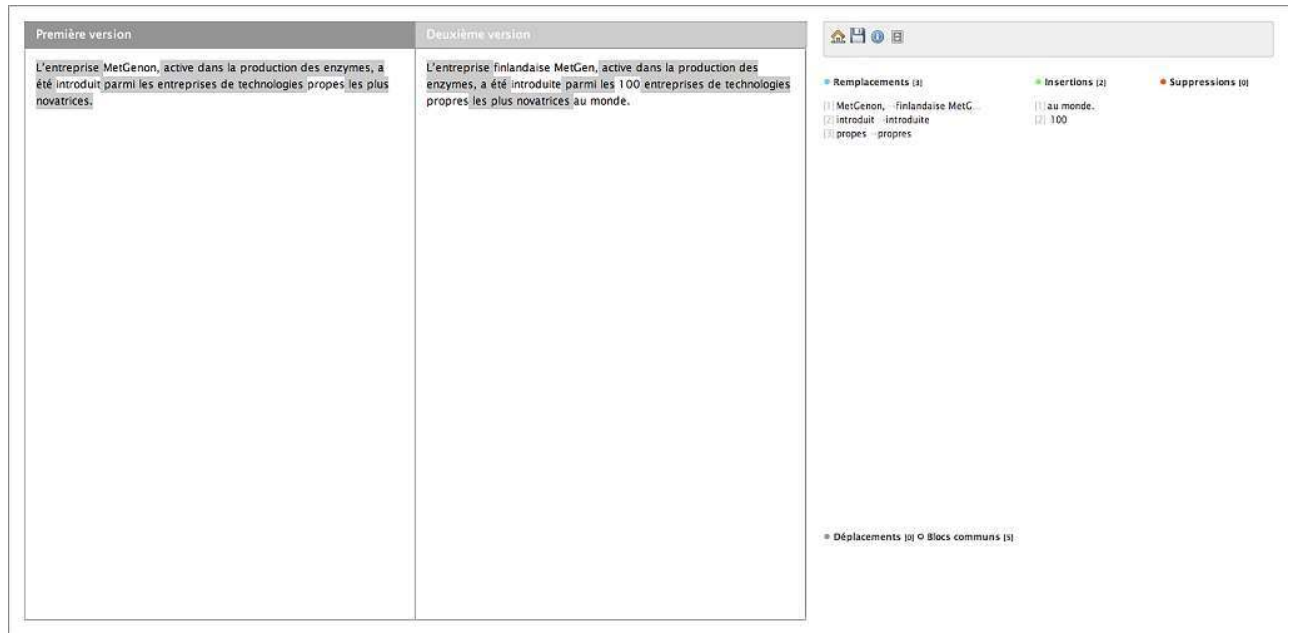




\section{Exemple-type 2}

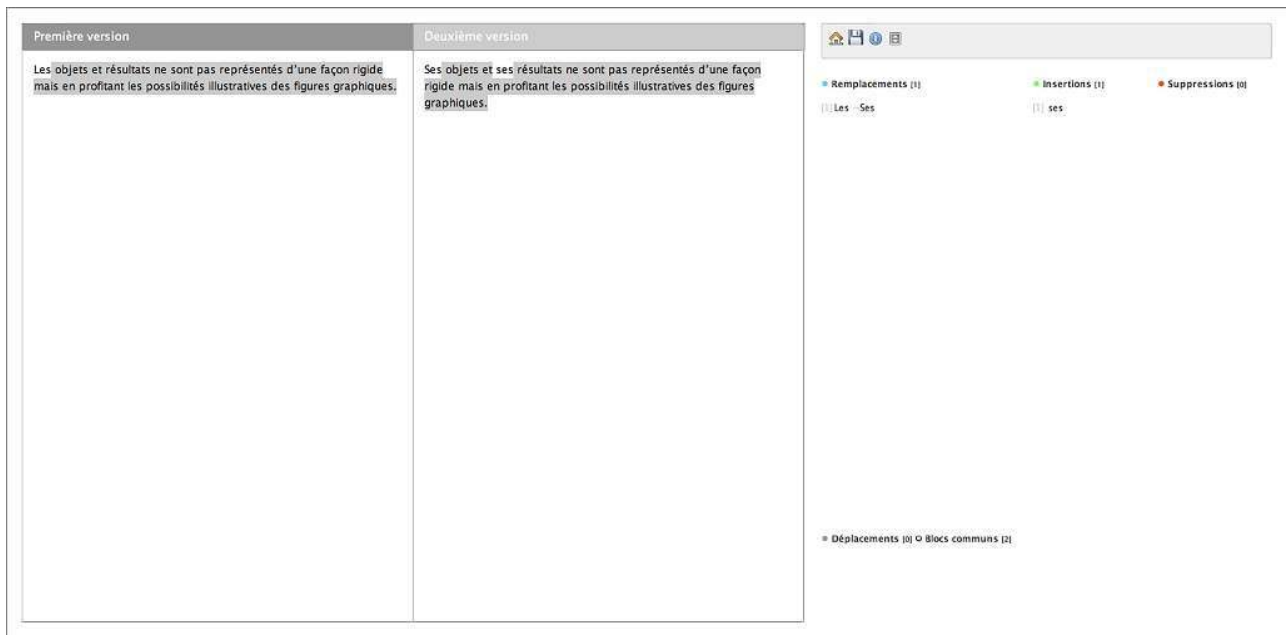

Exemple-type 3

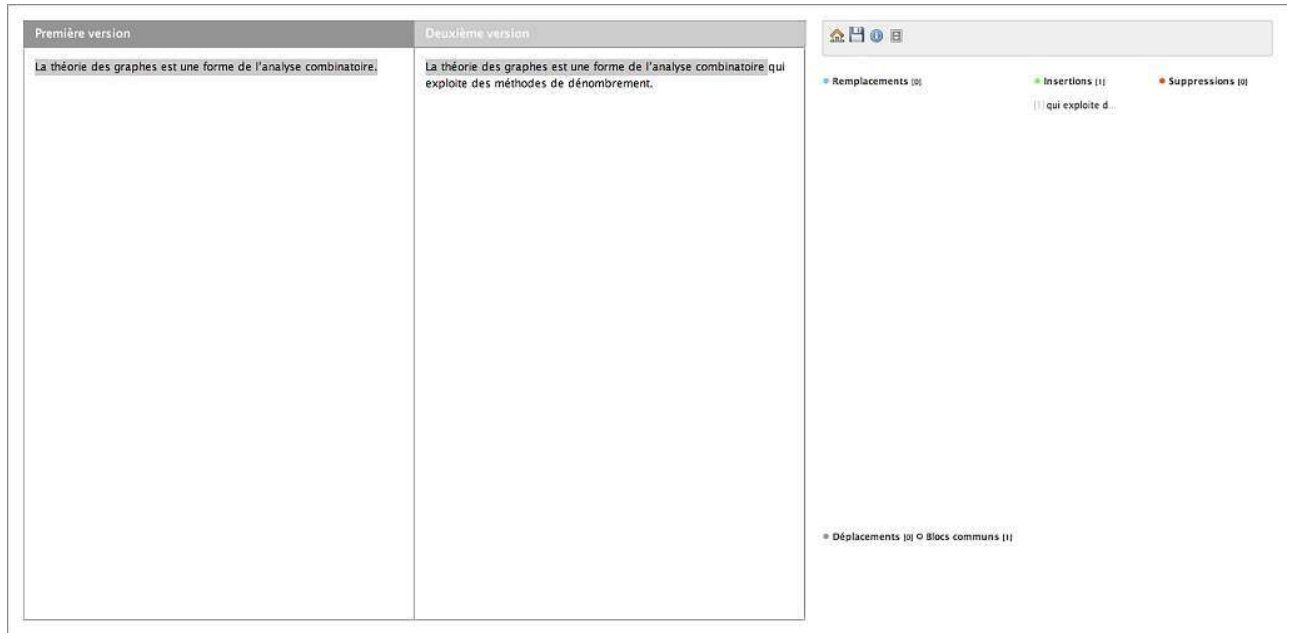

Exemple-type 4

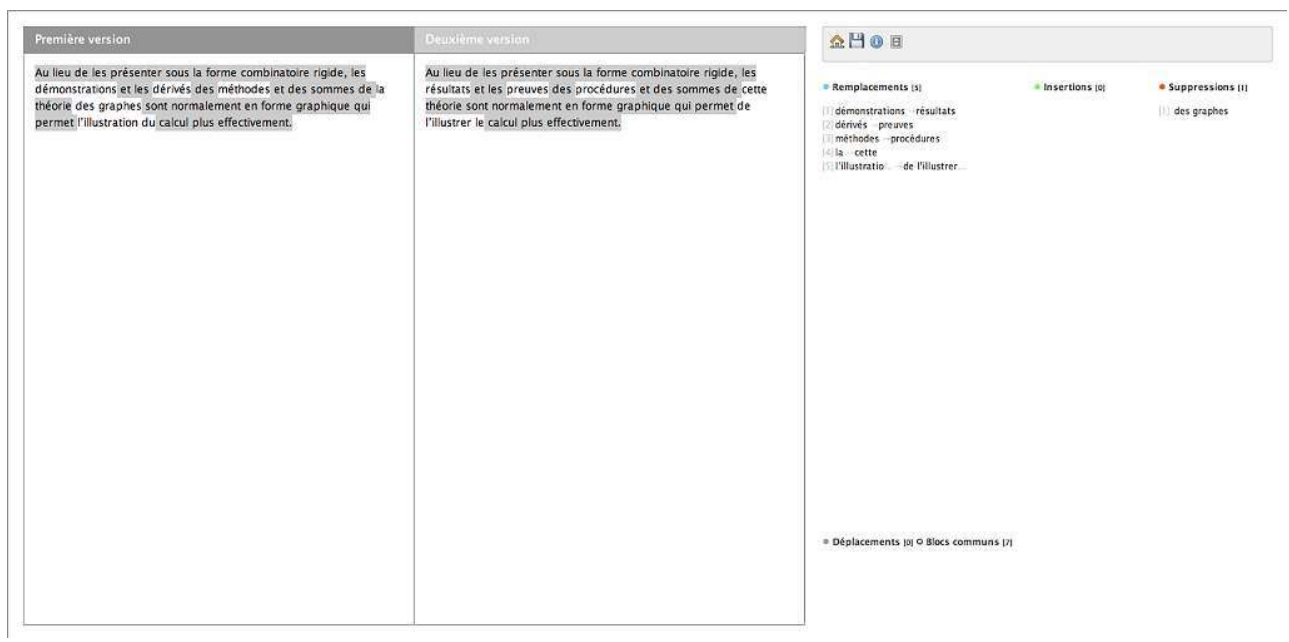




\section{NOTES}

1. Il n'entre pas, dans le cadre de ce travail, de distinguer nettement réécriture et révision. Nous nous contentons seulement de souligner que le terme de réécriture est davantage cité dans des travaux de génétique textuelle, quand le terme de révision l'est davantage dans des approches de psychologie cognitive. Nous utiliserons donc de préférence le terme de réécriture.

2. Référence du cours : Käännösviestintä ja toimeksiannot II, Suomi-Ranska, automne 2014 \& 2015, Département de Langues et de traduction, Université de Turku.

3. La seule limite est celle du temps. Les traducteurs professionnels connaissent très bien la pression exercée par un commanditaire pour rendre un travail à une date précise. Cette exigence, bien qu'elle soit le plus souvent considérée comme marque d'une pratique professionnelle, concerne le monde de l'écriture dans son ensemble.

\section{RÉSUMÉS}

Cette contribution se propose d'étudier le phénomène de reformulation dans un corpus de production-traduction, du point de vue de la génétique textuelle. Le déjà-là est alors doublement présent : une première fois, sous la forme du texte-source, donné en finnois, et une seconde fois, sous la forme d'une proposition discutée en français, par les étudiants et l'enseignant. L'idée a bien été d'introduire du déjà-dit et du déjà écrit afin de pouvoir en mesurer l'impact sur les réécritures-traductions. Nous nous attacherons, dans ce travail, à mettre en évidence certains phénomènes de reformulation (écritures nouvelles référées à des écritures antérieures), en pointant précisément des chaines d'occurrences présentes dans les deux réécritures-traductions.

This study sheds light on the phenomenon of reformulating in a corpus of writing and translation process from a genetic criticism perspective. In this study, the already-there is then doubly present: a first time, in the form of the source text, given in Finnish, and a second time, in the form of a proposition discussed in French, by the students and the teacher. The idea was to introduce already-said and already-written in order to be able to measure its impact on the rewritings-translations. In this work, we will endeavor to highlight certain phenomena of reformulation (new writings referred to earlier writings), pointing precisely to the chains of occurrences present in the two rewritings-translations.

\section{INDEX}

Mots-clés : déjà-là, génétique textuelle, réécriture-traduction, reformulation, scripteurtraducteur

Keywords : genetic criticism, reformulating, writing and translation process 


\section{AUTEURS}

\section{CHRISTOPHE LEBLAY}

Université de Turku, Finlande, ITEM, ENS-CNRS, Finlande, FI-20014

\section{TARJA LEBLAY}

Direction Générale de l'Enseignement, Finlande, FI-20014 